\title{
Gestão do conhecimento e prevenção a acidentes ambientais: estudo sobre as práticas de aprendizagem organizacional em empresa do setor de petróleo
}

\author{
Heitor José Pereira, Dr \\ Pontifícia Universidade Católica do Paraná - PUC \\ heitor.pereira@pucpr.br \\ Paulo C. Dondoni, Dr \\ Terezinha L. Detoni, $M S c$. \\ Centro Federal de Educação Tecnológica do Paraná - CEFET / PR \\ detoni@terra.com.br
}

\begin{abstract}
A evolução da economia e a crescente utilização de recursos naturais têm trazido modificações ao meio ambiente em relação à devastação e à destruição do ecossistema em função dos processos utilizados na transformação. Este artigo busca avaliar se práticas de aprendizagem organizacional impactam nos processos de prevenção aos acidentes ambientais. O método de pesquisa utilizado foi o estudo de caso e a pesquisa documental, na Petrobrás, Refinaria Presidente Getúlio Vargas - REPAR, de Araucária/PR, no período de 2000 a 2002, no qual intensificou a adoção de práticas de aprendizagem organizacional relacionada ao processo de prevenção de acidentes ambientais. $\mathrm{O}$ artigo aborda questões relacionadas à aprendizagem individual e organizacional, esta considerada como um processo de detecção e correção de erros. As indústrias tidas como possíveis poluidoras do meio ambiente vêm sendo pressionadas a atender aos aspectos legais, políticos e sociais, um grande desafio inerente a uma organização cuja atividade depende da extração da matéria-prima da natureza.
\end{abstract}

Palavras-chave: meio ambiente; aprendizagem; acidentes ambientais

The evolution of the economy and the increasing use of natural resources have brought modifications to the environment in relation to the destruction of the ecosystem, due to the processes used in the transformation. This paper evaluates whether the practices of organizational learning impact on the prevention of environmental accidents. The method adopt was the case study and documentary research, at Petrobras, Refinery Presidente Getúlio Vargas - REPAR, of Araucária/PR, from 2000 to 2002, when the practice of organizational learning related to the prevention of environmental accidents was intensified. The paper discusses how individual and organizational learning contributed to the process of detection and correction of errors. Industries with the potential for environmental pollution are being pressured to attend legal, social and political demands, what is a great challenge to an organization whose activity depends on the extraction of a natural resource.

Keywords: environment; learning; environmental accidents

\section{Introdução}

Nas últimas décadas do século XX e início do XXI, as mudanças no modo de gestão das empresas, sejam elas publicas ou privadas, receberam formatações marcantes de diferentes abordagens estratégicas.

As iniciativas para o aumento de eficácia juntaram-se a formas de responsabilidade para com a sociedade das mais variadas formas. Modelos gerenciais foram anexados como alternativas de aprendizagem e também como formas de posicionarem-se frente ao mercado competitivo. A dinâmica do processo de aprendizagem organizacional em segmentos que exploram recursos ambientais vem se tornando de fundamental relevância para a existência sustentada, tendo em vista que o processo de 
transformação desses recursos naturais envolve alto risco ao meio ambiente. Essa é uma das razões pela qual o conceito de aprendizagem, historicamente muito discutido, vem sendo retomado com grande intensidade. A dinâmica do processo de aprendizagem organizacional em segmentos que exploram recursos ambientais vem se tornando de fundamental relevância para a existência sustentada, tendo em vista que o processo de transformação desses recursos naturais envolve alto risco ao meio ambiente.

A mudança é algo esperado para o progresso e evolução de qualquer sociedade. Porém, parafraseando Maquiavel (1992), o povo não abandona tão facilmente as formas antigas e, portanto, conduzir uma nova ordem é uma tarefa difícil. Tendo como premissa que a cultura é um elemento presente no ser humano, pode-se também acreditar que o trabalho forma uma cultura que, por sua vez, gera conhecimento. Para se precaver contra acidentes, sejam eles contra o patrimônio privado ou público, e principalmente aquele que pertence às pessoas externas a empresa, a REPAR construiu sistemas de prevenção e implantou estratégias como a Gestão do Conhecimento com a adoção de práticas de aprendizagem organizacional. Assim, a empresa busca transformar-se, seguindo o direcionamento de autores de prevenção de acidentes ambientais, com a noção fundamental de prevenção para que "eventos de riscos", ou seja, situações de riscos de acidentes nem potencial gerando acidentes concretos (FREITAS, 2000).

As organizações passam a se preocupar cada vez mais com análises mais abrangentes que as tradicionais formas de análise monocausais. Primeiro, porque é limitada, mas ainda se encontra esta proposta em documentos de registros de acidentes, como nas normas da associação brasileira de normas técnicas (ABNT) e na comunicação de acidente de trabalho CAT do Instituto Nacional do Seguro Social (INSS), na qual há um campo específico para o preenchimento do "objeto causador". É um método que segue a linha da dicotomia entre o ato e as condições inseguras, e raros são os casos em que causas subjacentes de natureza organizacional e gerencial são avaliadas. Para Freitas, com esta visão "impede-se que a análise de acidentes sirva como possibilidade de as organizações industriais aprenderem com seus próprios erros - o que recentemente vem sendo denominado de learning organizations - inibindo o potencial mobilizador de mudanças e melhorias das condições de segurança das empresas" (FREITAS, 2000, p. 50-51).

Aprender com os próprios erros ou através de simulações consiste em um elenco de recursos que favorecem a engenharia do conhecimento e, por sua vez, propicia uma nova e efetiva construção de conhecimento. O conhecimento torna-se um processo que desenvolve a dinâmica organizacional, o que faz com que a organização seja percebida como um processo de transformação permanente.

A crescente necessidade das empresas se engajarem em processos de proteção do ambiente externo, ou seja, a preocupação ecológica, fez com que estas desenvolvessem uma nova cultura para a inovação e aprendizagem, revendo suas estruturas e práticas de organização do trabalho, e assim emergem de interações contínuas e recursivas entre as dimensões do homem, empresa e os novos conhecimentos adquiridos durante o processo.

Observa-se ainda que os programas de prevenção a acidentes ambientais são, hoje, fatores estratégicos para empresas cujas atividades impactam no meio ambiente. Isso justifica este estudo, pois a REPAR conviveu, a partir do incidente, que por sua extensão, provocou danos econômicos, sociais e ambientais de grande envergadura que a levou a intensificar suas políticas estratégicas acerca da responsabilidade e da prioridade na prevenção a acidentes e enfatizou a adoção de atitudes pró-ativas em toda a cadeia produtiva

O escopo deste estudo buscou enfocar somente aspectos práticos do programa de Gestão do Conhecimento adotado pela empresa e, em específico, as práticas de aprendizagem organizacional apontadas a partir dos autores: Senge (1990), Garvin (1993) Fleury e Fleury (1995) e Argyris (1977), relacionando-as com as praticas presentes no processo de prevenção a acidentes na Petrobrás, na Refinaria Presidente Getúlio Vargas - Unidade de Negócios de Araucária/PR - REPAR, no período de 2000 a 2002. 


\section{A aprendizagem organizacional através de práticas}

A introdução ao estudo deste tema contempla a evolução gerencial como um dos grandes modelos estratégicos de gestão, aliado a aprendizagem organizacional como a ruptura de velhas convenções rotineiras e limitantes na organização, abrindo caminho para a aquisição do conhecimento e de sua competente gestão que passa, essencialmente, pelo compartilhamento dos conhecimentos individuais para a formação do conhecimento organizacional. $\mathrm{O}$ foco dessa literatura concentra-se no aprendizado do ponto de vista de processo, especialmente no gerenciamento de mudanças e não na estratégia em si. Apõe-se a definição de Garvin (1993, p.80) sobre a organização que aprende para iniciar esta pesquisa: "uma learning organization é uma organização capaz de criar, adquirir e transferir conhecimento e em modificar seu comportamento de maneira a refletir o novo conhecimento e insights ${ }^{1,}$.

A atenção sobre a frase da citação de Garvin (1993), que procura atender aos critérios de aquisição de conhecimentos e à mudança de comportamento, no pressuposto de que o aprendizado chegue ao trabalho a ser feito, também pressupõe a mudança no operacional como significativa para que sejam instaurados novos comportamentos com relação ao conhecimento.

Para Mintzberg (2000), existem afirmações de que até mesmo a organização que aprende está restrita, pois tende a enfatizar o que é constante e persistente ao invés do que é inovador e revolucionário. Esta é a característica da teoria do caos, representativa da tentativa de mudança de um panorama tradicional. A evidência da organização que aprende chama atenção para o fato de que as pessoas têm que aprender, mas também têm que continuar realizando seu trabalho cotidiano eficientemente, sugerindo que haja, efetivamente, um tempo para aprender e um tempo para explorar a aprendizagem anterior, ou seja, as atividades realizadas em seu trabalho, a aprendizagem a partir das experiências.

O termo organização de aprendizagem, da década de 70, é adotado com freqüência apenas como uma aspiração, embora muitas organizações ainda lutem para realizar seu potencial na prática. Segundo Mayo (2003, p. 154), a organização da aprendizagem é fundamental para o crescimento do valor dos futuros interessados e não é alguma coisa que simplesmente acontece, mas é algo que deve ser gerenciado.

Qualquer empresa que tenha aspirações ao sucesso no ambiente dos negócios de peso deve resolver um problema que identifica como básico: o sucesso no mercado cada vez mais depende do aprendizado. Mesmo assim, a maioria das pessoas não sabe como aprender e, segundo Argyris (2000), o aprendizado ocorre nas empresas através das pessoas que se encontram inseridas em seu meio, dispostas a mudanças e a assimilar novos conhecimentos. Para Argyris "a maioria da empresas não têm somente uma tremenda dificuldade em lidar com este dilema de aprendizado: elas não têm nem mesmo noção de que este dilema existe".

$\mathrm{O}$ aprendizado, visto de forma muito restrita, serve para identificar e resolver problemas, corrigindo erros no ambiente. A expressão learning (aprender) tem etimologicamente origem na língua inglesa que, por sua vez, tem origem no idioma arcaico ou anglo-saxão, derivada do indo-europeu leis, termo que significa "trilha" ou "sulco na terra". Aprender significa aumentar a capacidade da pessoa através da experiência ganha por seguir uma trilha ou uma disciplina. As organizações que aprendem são mais flexíveis, adaptáveis e competitivas na medida em que aprendem mais rápido que os seus concorrentes (SENGE, 1999, p. 37 - grifos no original). É importante registrar a sutil diferença percebida na literatura quanto às definições apresentadas pelos autores em relação a aprendizagem e ao aprendizado.

\footnotetext{
${ }^{1}$ Insight significa uma profunda ou clara percepção de uma situação; sentimento de entendimento; percepção; ser intuitivo; sexto sentido. Disponível em: <http://dict.die.net/> Acesso em: 2 fev. 2004. Para Kohler insight é: apreensão súbita da solução de um problema (Dicionário Enciclopédia Século XX, 1972).
} 
A aprendizagem é aquisição de conhecimentos e transformação de comportamentos em função de experiência, tentativa e erro. Skinner, usando o condicionamento, desenvolveu a teoria do condicionamento operante, ou seja, o comportamento é aprendido quando tem conseqüências positivas, ou seja, recompensa (Dicionário Mirador Internacional, 1975, p. 169). Percebe-se que a definição da aprendizagem expressa o processo e, a definição de aprendizado expressa o resultado de tal processo.

Diversas outras definições sobre a aprendizagem e o aprendizado são fornecidas na literatura, como por exemplo, a de Argyris (1982), ao comentar que o processo de aprendizagem passa por "detectar e corrigir erros" relacionando-se com a busca sistemática de forma que venham solucionar problemas e incrementar a eficácia e eficiência.

Garvin (1993) compreende a aprendizagem como derivada de um processo de melhoria das ações originadas de melhor conhecimento e compreensão. Fleury e Fleury (1995) entendem a aprendizagem como um processo de mudança que resulta de prática ou experiência anterior. Tal processo pode, ou não, manifestar-se em uma mudança perceptível de comportamento e incluir a aprendizagem individual, integrante de um todo organizacional.

Entretanto, Senge (1990), a partir da publicação A quinta disciplina, foi o autor que popularizou a noção de aprendizagem, a qual teve também como precursores Argyris e Schon que enfocaram a capacidade das organizações na criação, aquisição e transferência dos conhecimentos que, por sua vez, redundam em comportamentos modificados. A idéia inicial em descrever esta nova atividade a ser absorvida pela organização trazia o pressuposto de que:

Talvez a aprendizagem se tornará mais importante do que o controle. Muitos se referem às organizações emergentes como 'organizações baseadas no conhecimento' ou como 'organizações que aprendem': organizações inerentemente mais flexíveis, adaptáveis e mais capazes de continuamente 'reinventarem-se'. A base, porém, é a disposição do espírito do pensamento sistêmico como forma de incrementar o pensamento reducionista tradicional (SENGE, 1990, p.12 - grifo no original).

Como premissa de seu pensamento, o autor referenciado preceitua que as organizações funcionam da forma como funcionam porque as pessoas funcionam dessa forma, ou seja, nenhuma mudança organizacional significativa pode ser realizada sem que se efetuem profundas mudanças na forma de interagir e de pensar das pessoas.

Já Argirys e Schön (1996) salientam que o termo aprendizagem possui dois sentidos: o primeiro, é alguma coisa aprendida que tem sentido de produto, significando o acúmulo de informações na forma de conhecimento ou habilidade, ou seja, o que aprendemos; e o segundo pode representar também um processo, isto é, como aprendemos, referindo-se à atividade, à forma ou à maneira como aprendemos.

As organizações aprendem quando adquirem informações de qualquer tipo ou maneira, sejam elas na forma de conhecimento, compreensão, know-how, técnicas ou práticas. Para Argirys e Schön (1996), o esquema genérico da aprendizagem organizacional inclui o produto, que é o conteúdo informacional; o processo, que é a aquisição; o processamento e armazenagem da informação; e o aprendiz, a quem o processo de aprendizagem é atribuído. A resposta dos autores sugere como saída mudar a forma do pensamento e da ação conseqüente, o que virá alterar as práticas organizacionais.

Segundo Argyris (1996), as pessoas possuem dois tipos de teorias de ação: a teoria assumida e a teoria aplicada. A teoria assumida consiste no conjunto de crenças e valores que as pessoas possuem para conduzir as suas vidas. A usual é basicamente uma teoria produtora de atitudes defensivas, mantendo as pessoas ignorantes de suas ações e criando rotinas organizacionais defensivas - é o trabalho do faz-de-conta. A nova, por sua vez, considera como valores a busca de informações válidas sobre um tema ou problema, a definição de escolhas bem avaliadas e a responsabilidade de monitoração da implementação dessas escolhas (ARGYRIS, 1996). 
Considerando-se que a conscientização do interior e do exterior da pessoa é derivada da percepção que tem das muitas coisas que a rodeia, justifica-se que a descrição da teoria da percepção será útil na compreensão e na interpretação dos resultados auferidos na pesquisa. Apresenta-se o pensamento de Santaella:

Penso que a percepção é o processo mais privilegiado para colocar na frente do nosso pensamento a massa dos três elementos de que somos feitos: o físico, o sensório e o cognitivo. O papel cognitivo na percepção é desempenhado pelo julgamento perceptivo. Que características ele tem? 1) Ele existe num contínuo, isto é, não está separado dos outros fluxos mentais. Etimologicamente, o percepto tem o significado de apoderar-se, recolher, tornar, apanhar, alguma coisa que é tomada de fora, e que está inerente ao homem, conforme exposição de Peirce ${ }^{2}$ (CP 7.642, apud SANTAELLA, 1998, p. 97): "Nada podemos saber sobre o percepto, a não ser pelo testemunho do julgamento da percepção, exceto pelo fato de que sentimos o golpe do percepto, a reação dele contra nós".

Senge (1999) situa as capacidades que dão suporte à utilização das cinco disciplinas de aprendizagem pela organização: domínio pessoal, modelos mentais, visão partilhada, aprendizagem em equipe, pensamento sistêmico e aprendizagem em equipe.

Essas capacidades exibem a presença da percepção, como, por exemplo, a aspiração - que é a capacidade de orientar, individual e coletivamente, em direção ao que as pessoas realmente desejam, com base em domínio pessoal e desenvolvimento de visão compartilhada.

Na capacidade de compreensão da complexidade, Senge (1999) define-a como a capacidade de ver padrões que dependem de problemas e de distinguir as conseqüências entre o curto e o longo prazo, que resulta de ações que tenham sua origem no pensamento sistêmico. Ressalta o autor referenciado que essas capacidades de aprendizagem não podem ser forçadas, apressadas ou impostas, pois que a aprendizagem leva tempo e exige prática, além de depender da decisão e escolha das pessoas. Desse modo, é pertinente lembrar das percepções que as pessoas têm das forças que moldam suas intenções sociais: forças tangíveis como regras, papéis e sistemas de recompensas, e forças intangíveis, como poder, orgulho e atenção ao detalhe (SENGE, 1999). Como essa síntese ocorre, é o problema da percepção.

O entendimento de Gibson (1974) sobre a percepção evoca uma teoria desenvolvida no final do século XVII por empiristas ingleses de que não há outra porta de entrada para o conhecimento humano que não seja a dos sentidos. Assim, asseguraram que as idéias humanas são apreendidas, e não implementadas na mente por magia e força divina e, magnificamente, registra: “... a mente, ao nascer, é como uma página branca, uma tábula rasa ${ }^{3}$, na qual a experiência vai registrando seus aprendizados" (SANTAELLA, 1998, p. 24).

A sensação não é controlada no momento da percepção e a forma de apreensão do visível pela pessoa ocorre no momento em que visualiza o objeto, enquanto que a sensibilidade é obtida pelos seus sentidos, comenta Merleau-Ponty (1999) ao afirmar que o comportamento acha-se escondido pelo reflexo, e assim como a teoria do arco reflexo, a fisiologia da percepção começa por admitir um trajeto anatômico que conduz de um receptor.

Para Senge (1990, p.167), “As organizações só aprendem por meio de indivíduos que aprendem. A aprendizagem individual não garante a aprendizagem organizacional. Entretanto, sem ela, a aprendizagem organizacional não ocorre".

Argyris et al. (1998, p. 59) define a organização que aprende como aquela particularmente hábil no aprendizado do conhecimento organizacional, intuindo que, nessa organização: o aprendizado não é meramente intuitivo, mas intencional, eficaz e conectado ao objetivo e à estratégia propostos; o

\footnotetext{
2 PEIRCE, C.. Sanders. (1931-1966) Collected Papers (CP), C. Hartshorne, P. Weiss and A. W. Burks (eds.). 8 vols. Cambridge, MA: Harvard University Press.

${ }^{3}$ Tábula rasa é o mesmo que negar que as pessoas nasçam com talentos, temperamento, e que a mente toda seja produto da cultura e da socialização (TVEBRASIL, 2003).
} 
aprendizado é oportuno, prevê desafios, ameaças e oportunidades; o aprendizado cria flexibilidade e agilidade para que a organização possa lidar com a incerteza; as pessoas se consideram capazes de gerar continuamente novas formas de criar os resultados desejados e as mudanças que caminham lado a lado com o aprendizado criam raízes.

Organizações que adquirem essas qualidades pró-aprendizado, utilizam-se de algumas práticas diferenciadas, dentre as quais, o cultivo da visão holística ${ }^{4}$ das coisas que fazem com que as organizações complexas funcionem, das coisas que fazem a mudança criar raízes e de como usar a lógica dos sistemas no diagnóstico de necessidades visando projetar novas ações para a eficácia do aprendizado e garantia de mudança, permanente. Complementam Argyris et al. (1998) que essas organizações reservam esses insights a uma participação ampla na geração do conhecimento e na criação de mudança. Visam, deste modo, criar o desejo e o entusiasmo pela mudança contínua, um envolvimento que venha melhorar a eficácia das ações, pois os insights múltiplos entram em ação aumentando a flexibilidade e a agilidade da organização.

Dentre as inovações inerentes à organização, Mayo (2003, p. 151) comenta a existência de um ambiente estimulador que inclui, dentre outros, a análise e a avaliação de sugestões por pessoas abertas a idéias, erros cometidos da experimentação nunca são penalizados, bem como o tempo e o dinheiro são disponibilizados para a experimentação e as pessoas, em geral, têm poder de decisão para fazer mudanças sem necessidade de autorização prévia.

A ressalva de Mayo (2003, p. 152) é com referência à disciplina nas práticas de trabalho e, oportunamente, destaca Drucker $^{5}$ (1992) em sua argumentação sobre a inovação e sua relação com um trabalho sistemático, dando ênfase a um "ouvir contínuo", benchmarking e à percepção de feedback"todos os aspectos-chave do processo de aprendizagem da organização".

As práticas ou ferramentas para a aprendizagem organizacional, bem como atividades afins, são os meios operacionais e estratégicos que possibilitam à organização a aprender. Autores como Senge (1990), Garvin (1993, 2001), Fleury e Fleury (1995) e Argirys (1996), também se posicionam sobre as práticas. Por sua vez, as práticas são atividades nas quais os praticantes da disciplina concentram seu tempo e energia. As práticas são atividades exercidas por grupos; os princípios devem ser entendidos pelos grupos e as essências são estados de ser experimentados coletivamente, assim veiculadas: Domínio Pessoal, Modelos Mentais, Visão Partilhada, Aprendizagem em Equipe, Pensamento Sistêmico.

A abordagem de Senge (1990) considera fundamental o desenvolvimento de organizações centradas na aplicação de cinco disciplinas, destacando três níveis distintos: $i$ ) práticas: o que você faz; ii) princípios: idéias orientadoras e novas idéias, insights; iii) essências: o estado de ser daqueles que possuem altos níveis de domínio da disciplina.

Contudo, Garvin (1993) apresenta uma outra versão das práticas de aprendizagem organizacional, acreditando que as práticas da aprendizagem organizacional vinculam-se estreitamente com a experimentação, com ações práticas e com o vivenciamento direto das práticas, ainda que estas ocorram por parte de outras pessoas, mas que estejam ao alcance das oportunidades de aprendizagem, como é o caso de aprender aproveitando-se das experiências acumuladas.

Garvin (1993) reconhece como práticas de aprendizagem organizacional: solução de problemas de maneira sistemática: é a prática que baseia-se na filosofia e nos métodos do movimento da qualidade, a experimentação: esta prática envolve a busca sistemática e o teste de novos conhecimentos, aprendizado com as próprias experiências: nesta prática as empresas analisam seus sucessos e

\footnotetext{
${ }^{4}$ A visão holística de uma empresa eqüivale a se ter uma "imagem única", sintética de todos os elementos da empresa, que normalmente podem ser relacionados a visões parciais abrangendo suas estratégias, atividades, informações, recursos e organização (estrutura da empresa, cultura organizacional, qualificação do pessoal, assim como suas interpelações) (Holismo, 2004).

${ }^{5}$ DRUCKER, Peter. Managing for the future. Oxford, Butteworth Heinemann, 1992.
} 
fracassos de maneira sistemática, e registram os ensinamentos de modo aberto e acessível para os membros da empresa, aprendizado com outros: nem todo aprendizado deriva de reflexões e autoanálises; às vezes, os insights mais vigorosos resultam da observação do ambiente externo que conduz ao desenvolvimento de novas perspectivas e transferência de conhecimento: é preciso que o conhecimento seja disseminado com rapidez e eficiência por toda a organização, evoluindo para além de um assunto local.

Lembra Garvin (1993) que, da mesma forma que no processo de aprendizagem individual, as crenças ou valores da pessoa precisam ser levados em consideração, também essas mesmas crenças e valores devem ser estendidas ao processo de aprendizagem organizacional.

Para Fleury e Fleury (1995), as práticas de aprendizagem organizacional envolvem:

i) o aprender pela análise do desempenho: a aprendizagem sempre dependerá da existência de mecanismos institucionalizados para gerar, registrar, analisar e interpretar as informações sobre o desempenho da produção;

ii) o aprender ao treinar: esta é a forma mais corriqueira de se pensar em aprendizagem. Mas não dispensa a reflexão detalhada, especialmente quando se consideram as formas não convencionais de treinamento formal em sala de aula;

iii) o aprender por contratação: as empresas, além de usar as formas de aprender que decorrem de forma intensa, podem apropriar-se também de conhecimentos e habilidades que estejam disponíveis no ambiente simplesmente contratando as pessoas que os possuem. Porém, esse processo de contratar pessoas para o óbvio nem sempre traz resultados positivos. Saber claramente qual é o tipo de conhecimento que se deseja, possibilita encontrar as pessoas adequadas;

iv) o aprender por busca: trata-se de conhecimento que não chega à empresa, "embutido nas pessoas", e nem sempre é transferido através de treinamento.

Uma das práticas apontadas por Garvin (1993), a aprendizagem com as próprias experiências, requer, primeiramente, a concepção das pessoas sobre o que realmente quer fazer. As teorias devem guiar a prática, e, então, a prática deve informar a teoria. Devemos estar sempre aprendendo e analisando, como um modo de ser da vida organizacional. (MINK et al. 1993, apud PRESKILL e TORRES, 2001, p. 133).

Os fortes valores retidos pelas empresas no tocante à melhoria do aprendizado e do desempenho mostram-as detentoras de suporte e recursos necessários para levar o aprendizado ao local de trabalho e, com isso, introduzir uma cultura de aprendizado ampla, diferente da cultura de treinamento, desenvolvendo argumentos convincentes para o aprendizado. Garvin (2002), ao retomar seus escritos sobre aprender com as próprias experiências, afirma que a prática traz a perfeição e que a experiência é o melhor professor, objeto de estudo por filósofos e centrado em duas escolas principais de pensamento: racionalista, com Descartes e Leibnitz, argumentando que o conhecimento é baseado em idéias e princípios inatos, conhecidos independentemente da experiência; empirista, representada por Locke, Berkeley e Hume, argumentando que o conhecimento vem apenas de percepções e dados sensoriais.

A primeira forma assegura que as mesmas tarefas sejam realizadas de forma mais eficientes com o passar do tempo. A ressalva, todavia, é de que muito da aprendizagem baseada na experiência ocorre sem nenhum raciocínio ou controle consciente, tema de estudo de engenheiros e economistas na obtenção de medidas concretas e acessíveis da experiência, agrupando as contribuições distintas da repetição e da exposição na chamada curva de aprendizagem.

Rosenberg (2002, p. 45) aborda o poder das simulações no aprendizado na prática, explicitando como as simulações ajudam a aumentar a autenticidade do programa de aprendizado, tornando o aprendizado mais transferível e motivador. Através das técnicas de simulação, é possível imergir os aprendizes em situações que realmente testam o que eles sabem, o que podem fazer e como eles pensam, de forma que experimentem o aprendizado muito além da simplicidade do acesso à teoria. 
Outra questão inerente ao aprendizado na prática é o realizado a partir dos erros, cujo treinamento oferece retorno para criar confiança e fornecer orientação, de modo que, por meio de cada ação inadequada, e de cada ajuste subseqüente, o aprendiz constrói uma estratégia cognitiva ou uma base de conhecimento interno para resolver o problema (ROSENBERG, 2002, p.46).

A aprendizagem por simulações é uma das medidas citadas por Garvin (2002, p. 130), no momento em que são substituídas as avaliações pós-fato por períodos alternados de aprender e fazer, com tarefas cotidianas do trabalho, pois estudos sugerem que "adultos absorvem melhor novas idéias quando são ligadas diretamente a desafios do dia-a-dia", considerando que a aprendizagem torna-se mais pró-ativa na combinação de três elementos: uma introdução a conceitos, teorias e ferramentas relevantes; um problema ou simulação cuidadosamente escolhido para testar e aplicar novos conhecimentos; e um processo que inclui pausas pelo caminho para avaliação de progresso, compartilhamento de aprendizagem e correções sistemáticas.

Os problemas simulados, na referência de Garvin (2002), oferecem solução, mas o contrário também se dá com problemas reais, embora estes tenham a desvantagem de não serem programados para a aprendizagem. Para Rodriguez (2002, p. 147), a cultura do medo de errar e da falta de confiança na organização deve ser afastada, devendo-se saber que, a partir de vários erros, uma nova idéia poderá surgir: cultura da confiança, do estímulo e da inovação deve prevalecer. Ao invés de incentivar a inovação, tais organizações sufocam as novas idéias e estimulam o medo de fazer. Para o autor referenciado, para uma organização, as pessoas devem ser estimuladas a fazer as coisas acontecerem, confiando em si mesmas e na organização.

A deterioração social e no ecossistema ${ }^{6}$ é produto do emprego economicamente dissipador dos recursos humanos e recursos naturais ${ }^{7}$, mas as estratégias de produtividade dos recursos podem praticamente deter a degradação da biosfera ${ }^{8}$, tornando-a mais rentável para empregar as pessoas e evitar a perda de sistemas vivos indispensáveis e da coesão social.

Com o surgimento de problemas como poluição ambiental, como a poluição do ar em áreas industriais e contaminação dos recursos hídricos ${ }^{9}$, nos países do Primeiro Mundo, Estados Unidos, Japão, Alemanha, Inglaterra, nas décadas de 60 e 70, surgiu também uma preocupação com a questão da gestão ambiental ligada a aspectos regionais específicos, associados a: padrão de desenvolvimento, segmentos industriais, matriz energética, combustíveis utilizados e disponibilidades de recursos naturais. O comportamento empresarial dos segmentos industriais de maior impacto ambiental sobre o meio ambiente, como o químico, o de papel e celulose, o siderúrgico e o de mineração, entre outros, no entanto, varia de empresa para empresa (HAWKEN, LOVINS e LOVINS, 1999, p. 5).

No atual contexto social, a conservação do meio ambiente e a prevenção de acidentes ambientais são temas de importância e relevância acentuadas em âmbitos legal, econômico e social. Segundo o Conselho Nacional do Meio Ambiente (Conama), considera-se impacto ambiental qualquer alteração das propriedades físicas, químicas e biológicas do meio ambiente, causada por qualquer forma de matéria ou energia resultante das atividades humanas que, direta ou indiretamente, afetam: I - a saúde, a segurança e o bem-estar da população; II - as atividades sociais e econômicas; III - a biota ${ }^{10}$; IV - as

\footnotetext{
${ }^{6}$ Ecossistema - conjunto integrado de fatores físicos, químicos e bióticos, que caracterizam um determinado lugar, estendendo-se por um determinado espaço de dimensões variáveis. Também pode ser uma unidade ecológica constituída pela reunião do meio abiótico (componentes não-vivos) com a comunidade, no qual ocorre intercâmbio de matéria e energia. Os ecossistemas são as pequenas unidades funcionais da vida (Semad, 2004).

${ }^{7}$ Recursos naturais: fontes de riqueza material e de biodiversidade que existe em estado natural, tais como florestas, reservas minerais e outros (Semad, 2004).

${ }^{8}$ Biosfera - sistema único formado pela atmosfera (troposfera), crosta terrestre (litosfera), água (hidrosfera) e mais todas as formas de vida. É o conjunto de todos os ecossistemas do planeta (Semad, 2004).

9 Recursos hídricos: numa determinada bacia, a quantidade de águas superficiais ou subterrâneas disponível para uso (Semead, 2004).

${ }^{10}$ Biota: Conjunto de flora e fauna de uma região. (Mirador Internacional - Enciclopédia Britânica do Brasil Publicações Ltda, $1^{\circ}$ vol. 1975).
} 
condições estéticas e sanitárias do meio ambiente; V - a qualidade dos recursos ambientais (Resolução Conama $\mathrm{N}^{\mathrm{o}}$ 001, de 23 de janeiro de 1986).

O biomimetismo ${ }^{11}$, ou seja, a redução do uso dissipador, a eliminação da própria idéia de desperdício, pode ser obtida redesenhando-se os sistemas industriais em linhas biológicas que modifiquem a natureza dos processos industriais e materiais, possibilitando a reciclagem constante do material em ciclos fechados contínuos e a eliminação da toxicidade (HAWKEN, LOVINS e LOVINS,1999, p. 9).

Demajorovic (1995,p.83) comenta, sobre a conservação do meio ambiente, que:

(...) após décadas de destruição da natureza, as companhias começam agora a mudar seus atos e iniciam projetos de reestruturação do meio ambiente. Algumas empresas já têm gerências ambientais acopladas às áreas de segurança do trabalho e saúde e, com isso, é possível criar uma responsabilidade sociocultural tanto nos funcionários como na comunidade vizinha à empresa .

As empresas começam a entender que a prevenção a acidentes ambientais é boa economicamente e também contribui para a construção positiva de sua imagem. Quando ocorre um acidente, o custo para a reparação é bem maior do que se fosse investido em prevenção - explica Demajorovic (1995, p.84).

Demajorovic (1995, p. 84) defende a construção do aprendizado. Segundo ele, é preciso investir no sistema educacional dos indivíduos, em um contexto organizacional para o aprofundamento de políticas eficientes que visem ao desenvolvimento sustentável. Apesar de ser um processo lento, o professor acredita que a consciência ambiental das empresas está mudando. Explica ainda que, nos últimos trinta anos, o modo do empresário ver o meio ambiental evoluiu, passando por três fases: a primeira, nos anos 70 , as companhias não faziam controle da poluição. Nos anos 80 , começaram a fazer controle da poluição, mas trabalhando no limite da legislação pelo receio de multas. Já nos anos 90, mudaram de uma ação reativa para pró-ativa, passando a fazer prevenção da poluição. Surgem os grupos de pressão pelo equilíbrio ecológico e os ecologistas, além de se preocupam com a poluição, ocupam-se com a preservação da espécie e com a nocividade da produção industrial, cuja atividade é freqüentemente considerada um obstáculo ao desenvolvimento econômico.

Andrade, Tachizawa e Carvalho (2003, p. 76) compreendem que os recursos humanos, em conjunto com os aspectos sistêmicos, processos e configuração organizacional, devem dar suporte às estratégias ambientais em nível de objetivos, identificando os trabalhos críticos ao sucesso do processo e estabelecendo objetivos para os produtos finais desses trabalhos.

Quanto ao projeto, consiste em projetar e organizar os cargos de modo que possam atingir os objetivos de modo eficiente e eficaz, sendo que ao gerenciamento cabe criar um ambiente de trabalho em que o pessoal capaz, treinado, tenha especificações claras, feedback regular, conseqüências positivas e poucas barreiras à realização dos objetivos.

Na interpretação dos autores, cabe à organização a adoção de políticas de recursos humanos, a permanente educação ambiental de seus empregados. A nível interno, a organização deve conduzir programas de educação continuada, contemplando a avaliação de impactos ambientais, dentre outras disciplinas. Recomendam ainda que, no plano externo, a organização, principalmente as pertencentes aos setores econômicos cujas operações empresariais estão sujeitas a maior impacto ambiental, pode adotar estratégias de educação participação da comunidade nos projetos ou empreendimentos de interesse comum, como: conservação dos solos; controle da poluição; utilização racional dos recursos naturais; exploração das fontes de matérias-primas de forma ecologicamente correta; e atividades correlatas (ANDRADE, TACHIZAWA e CARVALHO, 2003, p. 77).

São esses aspectos que devem nortear as definições das estratégias e políticas de recursos humanos, com coerência aos objetivos e estratégias ambientais da organização. Além disso, a incorporação da

\footnotetext{
${ }^{11}$ Biomimetismo usa a natureza para o desenvolvimento de novas tecnologias (Semad, 2004).
} 
variável ambiental como novo passo no ajuste competitivo das empresas, face às imposições da globalização econômica, é uma etapa que estabelece conexões com o acelerado processo de certificação de empresas brasileiras pela série ISO 9000, implementadora dos sistemas de gestão da qualidade. Por sua vez, a ISO série 14000 é um grupo de normas que fornece ferramentas e estabelece um padrão de Sistema de Gestão Ambiental, abrangendo seis áreas bem definidas: Sistema de Gestão Ambiental, Auditorias Ambientais, Avaliação de Desempenho Ambiental, Rotulagem Ambiental, Aspectos Ambientais nas Normas de Produtos e Análise do Ciclo de Vida do Produto.

A norma ISO/DIS14001 ${ }^{12}$ define desempenho ambiental como "resultados mensuráveis do sistema de gerenciamento ambiental, relacionados com o controle dos aspectos ambientais da organização e baseados em sua política, objetivos e metas" (Universidade Federal do Rio Grande do Sul, 2003).

Segundo Rossin (1986) mesmo com alguma mudança no comportamento e com atitudes de prevenção, os acidentes ambientais ainda ocorrem e podem ser divididos em dois grandes grupos: os dos desastres naturais causados por fenômenos da natureza, sem a intervenção do homem; e os dos desastres tecnológicos, gerados por atividades desenvolvidas pelo homem, tais como os acidentes nucleares, vazamentos durante a manipulação de substâncias químicas, entre outros.

Os acidentes industriais ampliados, segundo a Diretiva de Seveso ${ }^{13}$ de 1982 das Comunidades Européias são definidos como acidentes maiores. Anderson (1991 apud FREITAS, 2000, p.52) define que os acidentes são fenômenos complexos, exigindo a utilização e a integração de diversas abordagens específicas para atender ao amplo número de fatores que interagem entre si. Estas abordagens, oriundas de diferentes campos do conhecimento técnico-científico, estão inseridas em um processo de construção de modelos e metodologias integradas, cuja análise sofre adaptação ao fenômeno do acidente.

Sob essa perspectiva, Anderson (1991, apud FREITAS, 2000) explica que a visão científica do acidente ambiental pressupõe compreendê-lo, simultaneamente, em suas dimensões de caso único, sendo esta visão representativa de situações comuns, com características singulares e gerais, no âmbito social, tecnológico e epidemiológico dos acidentes.

Contudo, para Machado (1991 apud FREITAS, 2000), a idéia do acidente ambiental é um conceito difuso que tenta homogeneizar situações díspares, impedindo análises aprofundadas e contextualizadas. É fundamental que, a partir da reflexão sobre eles, formulem-se estratégias de controle e prevenção de futuras ocorrências de eventos similares, o que propicia o aprendizado. Perrow (1984 apud FREITAS, 2000) aborda a visão clássica de segurança, limitada no caso dos acidentes em indústrias de processos contínuos, onde trabalho envolve uma complexidade tecnológica bastante sofisticada. Esta visão clássica de segurança é denominada de sistemas complexos, ou seja, a ocorrência de disfunções em algum dos subsistemas leva ao efeito dominó, resultando em destruição do sistema ou parte expressiva dele.

Isto levou ainda à transição de segurança clássica, pautada em análises de acidentes já ocorridos num processo de aprendizado empírico, para uma abordagem sistêmica, de caráter prospectivo, ou seja, uma análise profunda, no intuito de avaliar e prever de forma quali-quantitativa a ocorrência dos acidentes.

\footnotetext{
${ }^{12}$ ISO/DIS14001 - Draft International Standard.

${ }^{13} \mathrm{O}$ acidente de 'Seveso' aconteceu por volta de meio-dia de um sábado, 10 de julho de 1976, com uma explosão em um reator TCP (2,4,5-triclofofenol), na unidade B da planta Industrial da Industrie Chimiche Meda Società Azionaria (ICMESA), situado na periferia da municipalidade de Meda, na Itália. Uma nuvem tóxica contendo TCDD (2,3,7,8-tetraclorodibenzeno-pdioxina), geralmente aceita como uma das substâncias químicas mais tóxicas produzidas pelo homem (Mocarelli et al. 1991), foi acidentalmente emitida no meio ambiente, contaminando seriamente uma área densamente povoada até seis quilômetros além do ponto do acidente, de acordo com a direção dos ventos e, com a largura de um quilometro. Este evento ficou conhecido internacionalmente como o 'desastre de Seveso'. O acidente contribui dramaticamente para o crescimento da preocupação pública acerca dos riscos industriais e acelerou a resposta regulamentadora acerca da segurança de instalações químicas (DE MARCHI, Bruna.; FUNTOWICZ, Sílvio.; RAVETZ, Jeromy. O acidente industrial ampliado de Seveso: paradigma e paradoxo, 2000, p. 129-30).
} 
A incorporação de métodos seqüenciais de análise de eventos desencadeadores de acidentes, descrita na árvore de causas e das falhas humanas, segundo Binder, Almeida e Monteau (1995 apud FREITAS, 2000) e Leplat e Terssac (1990, apud FREITAS, 2000), trouxe importantes elementos reestruturantes, permitindo uma abordagem interdisciplinar e complexa do acidente como fenômeno social, técnico e epidemiológico, embora ainda sem hierarquização dos componentes geradores dos acidentes.

As críticas feitas à análise tecnicista e à construção de novas abordagens provocaram um rompimento com as abordagens ainda presentes na engenharia de segurança no seu senso estrito. Uma nova forma sugere conceitos interdisciplinares e a base de uma abordagem que agregue, além dos aspectos sociais e técnicos do acidente, uma visão epidemiológica da saúde pública. Machado, Porto e Freitas (2000, p. 57), ao enfocar as opiniões de Perrow (1984) a respeito de responsabilização das vítimas pelos acidentes, enuncia uma classe de viés, já que o trabalho real requer que os trabalhadores ignorem as precauções de segurança visando à alta produção, ao cumprimento dos prazos estabelecidos e à manutenção de seu emprego.

\section{Metodologia da pesquisa}

Tendo em vista o objetivo geral e os objetivos específicos deste estudo, foi adotada a metodologia de pesquisa qualitativa (DENZIN e LINCOLN, 1997, p. 23). Para responder aos questionamentos e embasar o trabalho em estudo, foi adotado o método de pesquisa qualitativa e documental para levantar a história, a epistologia, os documentos, os atos e os fatos da organização, nos níveis gerencial e operacional. Para isso, utilizou-se questionamentos diretos e de entrevistas semi-estruturadas.

O método adotado para a elaboração da presente pesquisa é empírico, predominantemente qualitativo, enfocado um estudo de caso (YIN, 2001, p. 32). Para a abordagem, o método escolhido foi o indutivo (LAKATOS, 2001). A pesquisa foi apresentada de forma descritiva, com base em seus objetivos, que se propuseram a aumentar o nível de conhecimento sobre aprendizado organizacional e o impacto ocorrido no processo de prevenção de acidentes ambientais na organização em estudo.

A pesquisa foi feita a partir de levantamento, do tipo seccional e avaliação longitudinal, considerandose a necessidade de avaliar a percepção dos níveis gerencial e operacional da REPAR no período de 2000 a 2002. O nível de análise foi o organizacional e a unidade de análise foi constituída por grupos de pessoas que fazem e/ou fizeram parte do nível gerencial e operacional da organização em estudo, no período já referido.

A pesquisa foi realizada por meio da coleta de dados primários e secundários. Os dados primários foram coletados mediante a realização de entrevistas semi-estruturadas, no nível gerencial e nível operacional, pois esse tipo de entrevista permite captar as percepções, opiniões e interpretações da realidade organizacional pelos indivíduos.

Um roteiro básico foi seguido pelos pesquisadores a partir dos indicadores das categorias analíticas especificadas e das informações coletadas nas fontes secundárias. Os dados secundários foram obtidos em programas, projetos, informativos, revistas, documentos, controles e normas, afetos à organização em estudo.

O tratamento dos dados foi efetuado de forma descritiva e analítica, tendo em vista a abordagem predominantemente qualitativa adotada no delineamento da pesquisa. Os dados primários foram analisados mediante a utilização da técnica de análise de conteúdo (BARDIN,1979, p. 42).

Sendo a pesquisa um estudo de caso único, cabe ressaltar alguns aspectos referentes a sua limitação: o segmento escolhido para a pesquisa empírica é uma refinaria de óleo e se a pesquisa abarcasse todos os níveis tornaria o estudo interminável e fora do foco que se propôs para este estudo. 


\section{Apresentação dos dados e discussão dos resultados}

A Unidade de Negócios REPAR, em sua busca da auto-aprendizagem, e de compartilhamento do conhecimento tácito e explícito, por meio da aprendizagem de equipes, a transformação em novo conceito, pela aprendizagem por experimentação e a validação do novo conhecimento para sua disseminação e uso por meio da aprendizagem organizacional, são componentes da criação do processo de gestão do conhecimento, constante na Agenda de mudanças - Projeto 7 (2001, p. 40).

Para a Petrobras (2001), a aprendizagem organizacional tem como objetivo permitir que a empresa seja capaz de aprender mais rápido e melhor, buscando garantir vantagens competitivas sustentáveis, garantir poder de adaptação frente a novas realidades, redirecionando a empresa para superar obstáculos e atingir os resultados desejados.

Tais objetivos consistem em: avaliar a situação atual e os fatores que a condicionaram; visualizar os possíveis cenários de futuro e selecionar a situação desejada; planejar e implementar ações para se mover da situação atual para a situação desejada. É um processo organizacional contínuo e cumulativo que pode acontecer na empresa em diversos níveis, em função de seu ciclo de vida e de seu contexto de atuação, caracterizando-se como estágios de: aprendizagem de manutenção; aprendizagem adaptativa; aprendizagem transacional e aprendizagem criativa (AGENDA DE MUDANÇAS, 2001, p.73).

O ciclo da Gestão do Conhecimento (GC) na Petrobras utiliza-se de seis processos cujas etapas são:

- a identificação

- a coleta

- adaptação a criação

- a organização e preservação

- o compartilhamento e a utilização

Com a aplicação dessas etapas, a situação desejada dos fatores facilitadores pela Petrobras, é a seguinte: que os princípios de GC sejam disseminados em todos os níveis da Petrobras, que as pessoas e as equipes saibam que seus conhecimentos agregam valor aos resultados da Companhia e estão comprometidas com os objetivos estratégicos da organização.

Segundo o documento examinado, existe uma cultura de desenvolvimento e retenção de competências, e uma forte motivação para aprendizado e auto-desenvolvimento, pois a criação, preservação e compartilhamento do conhecimento são valores reconhecidos na Companhia. Além disso, constata-se que existe uma cultura de aprender com os acertos e os erros e uma preocupação permanente com a disseminação e utilização das melhores práticas.

Desta forma, a organização promove a interação das unidades organizacionais, incentivando a geração de novos conhecimentos e o ambiente tecnológico de suporte à Gestão do Conhecimento permite que a busca, a organização, a recuperação e a utilização do conhecimento seja realizada, por meio de interfaces seguras e amigáveis e independentemente da localização geográfica.

Estão ainda presentes no documento examinado que as práticas de aprendizagem organizacional, através de grupos de discussão e as comunidades de conhecimento se utilizam de ferramentas de apoio à colaboração e compartilhamento. Tais ferramentas dão suporte à geração de idéias e de criação de conhecimentos disponíveis para as equipes, de acordo com suas necessidades (AGENDA DE MUDANÇAS, 2001, p. 46-7). São estas informações que creditam a Petrobras na busca da aprendizagem organizacional na empresa. Na seqüência, são apresentadas as práticas de aprendizagem, delimitadas, especificamente, algumas delas propostas na Agenda de Mudanças (2001). 
Na Petrobras, regem os princípios de que a aprendizagem com os acertos e erros e o pensar diferente são decisivos para a manutenção de um ambiente propício à Gestão do Conhecimento, o alinhamento das práticas de Gestão do Conhecimento com as estratégias corporativas e de negócio é a garantia de sua eficácia, a aprendizagem contínua e o auto-desenvolvimento são valores fundamentais para os empregados da Companhia, bem como a disseminação e o emprego das melhores práticas são fundamentais para a obtenção da excelência empresarial (AGENDA DE MUDANÇAS, 2001, p. 15).

Encontra-se no documento examinado que a Petrobras busca atingir os objetivos de aprender com os acertos e erros das experiências decorrentes de ações regulares dos processos internos da organização por meio de Registro e Disseminação de Lições Aprendidas, com o que busca conscientizar as equipes e pessoas sobre o valor da reflexão sobre os acertos e erros dos processos e disseminar as lições aprendidas por toda a organização ou grupos de interesse, para replicar sucessos e evitar a repetição dos erros. Tal fato consta na Agenda de Mudanças, conforme citado na íntegra a seguir: O registro e a disseminação de lições aprendidas é uma prática simples que pode ser aplicada a indivíduos e equipes, como mecanismo de aprendizagem e captura de conhecimento resultante do sucesso ou fracasso de experiências. Consiste em responder quatro questões básicas: $i$ ) o que era esperado acontecer? ii) o que realmente aconteceu? iii) por que aconteceram desvios entre o que se pretendia e o que realmente aconteceu? iv) O que se pode aprender com esta experiência? (AGENDA DE MUDANÇAS, 2001, 52).

A Petrobras registra no documento examinado que o processo de aprendizagem a partir das lições aprendidas compreende a identificação dos desvios, positivos ou negativos, pontos fortes e fracos da experiência; registro das lições aprendidas, reflexão sobre oportunidades para melhoria e proposição de recomendações para ações futuras de mesma natureza; documentação e organização das lições aprendidas; identificação de meios de comunicação para disseminação das lições aprendidas, integrando esta prática de Gestão de Conhecimento a outras que a complementam, como por exemplo, comunidades técnicas (AGENDA DE MUDANÇAS, 2001).

Na Petrobras, o objetivo da utilização da prática de aprendizagem benchmarking é obter e sustentar vantagens competitivas pelo domínio das melhores práticas do ramo de negócio em que a empresa está inserida e pela adaptação de melhores práticas de outros ramos de negócio, buscar a melhoria continua em seus processos, produtos e tecnologias por meio da comparação com referenciais externos de excelência.

Com relação a prática registrada no documento examinado, a Universidade Corporativa Petrobras, encontra-se estruturada na construção de programas de educação continuada que visem a atender as estratégias da organização, baseados em eixos de desenvolvimento de competências organizacionais, que passam pelo desenvolvimento de cultura e valores para toda a empresa e para os clientes e demais elementos que interagem com a empresa (AGENDA DE MUDANÇAS, 2001).

Uma outra prática utilizada na Petrobras para a gestão do conhecimento são as comunidades técnicas registradas no documento examinado como redes de pessoas que trabalham juntas e que compartilham regularmente informações e conhecimentos em determinado campo de atividade da empresa. Tais redes são mantidas por objetivos comuns e necessidades de seus integrantes aprenderem uns com os outros.

Em documento analisado sobre planos de contingência na REPAR, encontrou-se registrado que para a aferição da capacidade da resposta e de aprimoramento dos planos de contingência, a organização utiliza-se de simulados criando cenários de acidentes ambientais através de um planejamento de cerca de 15 dias anterior ao simulado, em que é analisado o plano de contingência da unidade e checados todos os seus itens (REVISTA PETROBRAS, 2003).

Em registro documental, constatou-se que foram realizadas no final do ano de 2003, no parque de GLP - gás de cozinha - com a participação da comunidade, as preparações para o desenvolvimento de um grande simulado de emergência. Relata o coordenador do simulado que: "é uma responsabilidade 
enorme da refinaria envolver a comunidade em um simulado de emergência, mas, por outro lado, também é importante que isso aconteça por causa da localização do bairro" (REPAR, 2003).

No passado, a realização de outros simulados pela empresa foi um sucesso, com a montagem de um plano de fuga da comunidade. O evento teve duração de três horas e teve um realismo "impressionante", segundo a REPAR (2003).

Para disseminar o conhecimento, o SMS corporativo produz relatório e vídeo sobre cada simulado usados nas unidades onde ocorrem. A justificativa é a de que "o simulado não programado é um compromisso com a excelência, meio ambiente e saúde na Petrobras", os exercícios são um sistema de avaliação e aprimoramento que visa aumentar a transparência da companhia diante de suas eventuais deficiências e também perante a sociedade, e aproxima a gestão da companhia da realidade das emergências, fazendo o sistema de proteção ambiental da organização "uma rede viva, dinâmica, em processo permanente de capacitação, em todos os níveis" (REVISTA PETROBRAS, 2003, p. 27).

Desde 2000, a Petrobras possui células fotossensíveis e sensores de fumaça em todas as áreas críticas da refinaria; em centros de controle, computadores vão comparar os volumes transportados por toda a rede em busca de diferenças de fluxo, o que permite a identificação de vazamentos muito antes que se caracterize um acidente ambiental, conforme dados dos Cadernos Petrobras. Mais importante do que os modernos equipamentos, é a questão cultural de que, segurança no trabalho é um compromisso de todos os empregados de toda a empresa.

Os resultados da pesquisa documental na REPAR refletem o direcionamento que a Petrobras tem tomado, a partir de 2001, quanto à gestão do conhecimento e à utilização de práticas de aprendizagem na organização. Tais documentos examinados evidenciam que as ações adotadas pela REPAR são posteriores ao ano de 2000, indicando que a ocorrência do derrame de óleo desencadeou um processo de mudança na organização, voltando-a à adoção das práticas de aprendizagem organizacional nos processos de prevenção a acidentes ambientais.

Para a pesquisa de campo optou-se pela realização de um teste de validação do estudo aplicado no nível gerencial, respondido por 11 (onze) dos 21 gerentes, visando identificar se a REPAR possui características de uma organização que aprende. Utilizou-se o instrumento de pesquisa formulado por Guns (1998), no qual há atribuição de pontos às questões formuladas, de 1 a 5, correspondendo a:1= baixo, $5=$ alto.

Quanto ao tempo de serviço, a variação no período excede aos 29 (vinte e nove) anos. Observa-se que 93,55\% dos entrevistados, computando-se o tempo de serviço de mais de 3 (três) anos, exerciam atividades na empresa no ano de 2000, confirmando-se a presença desses entrevistados, no período de ocorrência do derrame de óleo que levou a REPAR a desencadear uma série de providências para a formulação de estratégias voltadas à responsabilidade ambiental, com estudo sobre as conseqüências no meio ambiente resultante dos acidentes com agentes químicos, implementando a prevenção a acidentes e introduzindo, a partir da análise do erro, a aprendizagem no âmbito da organização.

Observando-se que, do total da amostra, 23 entrevistados estão na empresa há mais de 10 (dez) anos, é possível pressupor que estes pertencem a uma época em que a filosofia de gestão empresarial compunha-se de estratégias que visassem redução de custos, apenas, tal como cita Freitas (2000, p. 51) ao considerar que, com relação ao aprendizado, ainda se encontra instalada a concepção monocausal limitante do aprendizado na organização com suas falhas e que tende a culpar os trabalhadores pelos acidentes. Neste caso, não é observando a predominância de um método dicotômico em larga escala, e raros são os casos em que causas subjacentes de natureza organizacional e gerencial são avaliadas na REPAR, no período de 2000 a 2002 e analisar a relação existente entre as práticas de aprendizagem organizacional, apontadas na literatura e as implementadas no processo de prevenção a acidentes ambientais na REPAR, no mesmo período. 
O conjunto de dados a seguir, visa responder aos objetivos da pesquisa, os quais buscam identificar as ações do processo de prevenção a acidentes ambientais presentes na Repar no período de 2000 a 2002, identificar as práticas de aprendizagem organizacional, no nível gerencial e operacional, relacionadas com o processo de prevenção a acidentes ambientais na

Na primeira questão, a abordagem da pesquisa buscou saber se a empresa adota viagens técnicas para aprender com as experiências bem ou mal-sucedidas em outras empresas que atuam com processos semelhantes. As respostas obtidas permitem considerar como relevante o índice de 87,18\% para a alternativa "Sim", pois significa que a maioria dos entrevistados sabe que a empresa adota viagens técnicas como uma das práticas de aprendizagem. No entanto, para um índice de $10,26 \%$ a resposta é não, permitindo a pressuposição de que há desconhecimento sobre a adoção desta prática. A entrevista, porém, revelou nos depoimentos de quatro entrevistados, a não participação efetiva desta prática, pois não são todas as funções-chave da empresa que participam dessas viagens: "O profissional que realiza as viagens técnicas tem o dever formal de compartilhar os ensinamentos" (Entr $\left.{ }^{14} .10\right) ;$ "Eu especificamente, não efetuei viagens neste sentido" (Entr. 11); "Com viagens para outros países dos técnicos e engenheiros" (Entr. 23); "Os técnicos, gerentes e engenheiros viajam para Canadá, França e EUA" (Entr.24).

Percebe-se que os executores e operadores dos processos que, por vezes, teriam maior proveito com a viagem técnica, quer pela conscientização, quer pelo aprendizado, quer pela ampliação de horizontes, não têm participado dessas práticas. Contudo, essas mesmas viagens técnicas passam a compor os currículos dos gerentes, engenheiros que não se encontram diretamente em contato com a operação efetiva do processo, ou seja, esses empregados que participam das viagens técnicas trazem as metodologias, os procedimentos e os traduzem ao ambiente operacional do processo, embora não detenham a prática desse mesmo processo, criando uma dualidade discrepante entre a teoria e a prática. Portanto, aquele que vai aprender nas viagens técnicas, não sempre é o executor do processo, enquanto que aquele que pratica o processo apreende a teoria por meio de compartilhamento de informações de terceiros e não in loco, como melhor efetivaria o aprendizado.

Garvin (2000), ao abordar o aprendizado, afirma que a experiência é a precursora de toda educação verdadeira. Por sua vez, Dewey (1938) referencia em sua tese que problemas práticos asseguravam que não pode haver separação de matéria e método: o fazer é de natureza tal que exige raciocínio ou a anotação intencional de conexões; a aprendizagem resulta naturalmente disso.

Há que se ter cuidado, sobretudo, na aquisição e interpretação das informações compartilhadas, levando-se em conta a percepção muito particular a cada indivíduo e que tão bem Santaella (1998, p. 65) descreve o conhecimento do percepto através da mediação do signo ${ }^{15}$, que é o julgamento da percepção, frisando a manipulação do meio mental de ligação entre o que está fora e o juízo perceptivo, fruto de uma elaboração mental.

Na questão seguinte, objetivou-se identificar que contribuições os entrevistados têm recebido para o aprendizado com as viagens técnicas. As respostas foram concedidas de forma espontânea, categorizadas as cinco mais citadas, conforme segue: $i$ ) troca de informações/soluções; ii) novas tecnologias; iii) novos processos; iv) novas culturas e $v$ ) melhoria de técnicas operacionais.

Para a discussão das respostas categorizadas, atém-se à palavra "novo", acompanhada de tecnologias, processos e culturas, se repete em três depoimentos. Contudo, não serão menos importantes as outras falas dos demais entrevistados, com relação à contribuição que as viagens técnicas trazem ao aprendizado. Cabe, então, intuir da importância do aprendizado na execução desta prática de aprendizagem, considerando as prerrogativas de Allen (1977), que já afirmara o aprendizado

\footnotetext{
${ }^{14}$ Entr. Abreviamos a palavra "entrevista"

${ }^{15}$ Segundo Peirce, "um signo, ou representamen, é uma coisa que representa a outra em certo aspecto ou condição" e que "se dirige a alguém, ou seja, cria na mente dessa pessoa um signo equivalente ou mais desenvolvido" Qualquer coisa perceptível: palavra, sintoma, sinal, sonho, letra, frase. Um signo representa um objeto, refere-se ao objeto. Sem ele, é impossível conhecer o objeto. 2, p. 228, 1931-1966.
} 
individual como de importância significativa na aprendizagem organizacional através da entrada da informação na organização via transmissão pelo indivíduo. A apreensão de Allen (1977) dá-se no sentido de que pouca atenção é dispensada no sentido de esclarecer que fatores influenciam a aprendizagem individual e a relação destes fatores com a aprendizagem organizacional, no momento em que esta é restringida pela capacidade de interpretação de realidades complexas. Assim, quando o entrevistado refere como contribuição ao seu aprendizado individual por meio da prática de viagens técnicas a utilização de projetos bem-sucedidos, por exemplo, compreende-se que o sentido e os objetivos dessa prática estão sendo atendidos. Dessa forma, a discussão mostra o seguinte: as viagens técnicas como prática de aprendizagem na REPAR têm se conduzido satisfatoriamente no contexto da aprendizagem organizacional.

Sob outro aspecto, a inserção/implementação de novos modelos e projetos na organização, como o Programa $\mathrm{DDS}^{16} \mathrm{e} \mathrm{STOP}^{17}$ as visitas intencionais as $\mathrm{ONGs}^{18}$ e às Universidades vem ao encontro do alerta de Simon (1991) de que a eficiência do gerenciamento da aprendizagem envolve tanto a aquisição de novos conhecimentos como a eliminação de conhecimentos obsoletos e inúteis.

Para saber se existe troca de experiências, foi apresentada ao entrevistado uma questão com alternativas fechadas e de múltipla escolha. A análise é feita sobre a freqüência de respostas, considerando a multiplicidade e calculando-a sobre o total da amostra. As respostas destacam que a troca de experiências é feita com outras refinarias, com $97,44 \%$ de respostas e com outras empresas de áreas similares, com $64,10 \%$ de respostas.

A Agenda de Mudanças da Petrobras (2001) determina como uma das práticas de aquisição de conhecimento, a capacitação de pessoas através do desenvolvimento de programas que visam a redução e/ou eliminação, dos hiatos de competência, alinhados aos objetivos estratégicos da organização.

Em encarte da REPAR, sob o título Parceria com Universidades, a recuperação da área atingida pelo vazamento de óleo em 2000, imprimiu a celebração de vários acordos para estudos e atuação junto a universidades brasileiras, a UFRGS e UFPR, com assessoria de empresas canadenses, a Hidrogéo Plus e Sylvain Marcoux, possibilitando a pesquisa junto a peixes, anfíbios, répteis e mamíferos, atuação junto ao solo e à flora, estudo dos lençóis freáticos e um diagnóstico da gestão da Repar por mais de 100 professores de universidades paranaenses.

Para cada uma das alternativas propostas, foi elaborada uma nova questão - quanto à troca de experiências com outras refinarias - incluindo-se alternativas de respostas fechadas e de múltipla escolha, dentre as quais discutem-se os dados que confirmam que 92,31\% discutem experiências de situações semelhantes, enquanto que $79,49 \%$ discute a solução adotada naquela situação. Ocorre, também, a discussão dos erros de forma aberta, 53,85\%, discutem as dificuldades na adoção de soluções. Entretanto, 33,33\% admitem discutir a falta de pró-ação.

Ainda que as respostas declinadas resultem de múltipla escolha, destacam-se os dois primeiros atos que são praticados na troca de experiências com outras refinarias, inclusive com destaque para troca de experiências com a Shell ${ }^{19}$ e com a discussão de situações semelhantes, a exemplo do que cia Freitas (2000, p.56-7) sobre a importância da abordagem interdisciplinar, especialmente em casos de riscos industriais.

\footnotetext{
${ }^{16}$ DDS - Diálogo Diário de Segurança.

${ }^{17}$ STOP - Parada para refletir sobre procedimentos seguros em relação a processos de alto risco que envolvam também o meio ambiente.

${ }_{18}$ ONG's - Organizações não Governamentais envolvidas com prevenções a acidentes ambientais.

19 A Shell tem suas origens em 1833, numa pequena loja que vendia no East End de Londres antiguidades e objetos exóticos como belas conchas orientais, usadas pelas donas de casa para enfeitar caixas e móveis. A Shell de hoje é a maior empresa do mundo em negócios com óleo, e que realiza suas atividade no mercado brasileiro desde 1913. (www.shell.com, 2003).
} 
Cria-se então uma situação tal em que a troca de experiências acompanhada pela investigação interdisciplinar suplanta um simples somatório de diferentes profissionais e disciplinas científicas em torno de um problema, mas interfere no jogo dialético de interações entre as fases de diferenciação, nas quais predominam os estudos específicos e especialistas, que re-agregam resultados obtidos no momento anterior, redefinindo a concepção do próprio sistema estudado (FREITAS, 2000).

A alternativa seguinte, com índice de 53,85\%, estimando a discussão das dificuldades na adoção de soluções corretivas revela que há predisposição para a aceitação de mudanças, a partir da troca de experiências com outras refinarias.

Machado, Porto e Freitas (2000) apresentam duas considerações acerca de eventos, sendo que uma delas é a de que algumas dessas ações e decisões são estratégias relacionadas ao gerenciamento e controle da produção, com soluções táticas e realizadas imediatamente, enquanto que outras podem claramente ser erros, julgamentos considerados aceitáveis em determinados momentos, mas não eficientes.

Com as mesmas características da questão anterior, apresentam-se os resultados da questão sobre a troca de experiências com outras empresas de áreas similares, destacando-se que, $53,85 \%$ dos entrevistados, discutem experiências de situações semelhantes; $48,72 \%$ discutem a solução adotada naquela situação; 30,77\% discutem as dificuldades na adoção de soluções corretivas; $23,08 \%$ discutem os erros ocorridos abertamente; e, 17,95\%, discutem a falta de pró-ação.

Abordando as simulações preventivas, a pesquisa buscou confirmar sua ocorrência por meio de alternativas fechadas e de simples escolha, sendo que seus resultados mostram 97,44\% de respostas "Sim" e, 2,56\% de respostas "Não". Constatou-se que a maioria dos entrevistados concorda que as simulações preventivas são realizadas, significando o conhecimento por parte dos empregados da adoção desta prática de aprendizagem. Perguntado sobre a freqüência dessas simulações preventivas, as respostas que ocorrem em diferentes ocasiões, devido ao SMS organizá-las nos setores em se apresentem necessidades originadas pelos respectivos processos de produção e onde a área seja reconhecida como área de maior risco. Há casos, no entanto, dos setores administrativos e de manutenção, que realizam simulações preventivas apenas anualmente, por estarem localizados em áreas menos expostas a incidência de riscos. Contudo, é claro que todos os empregados, de todos os setores, participam do simulado anual, incluindo os visitantes e a comunidade, com processo de evacuação de comunidades próximas e com o apoio e participação de órgãos municipais e da defesa civil, médicos, bombeiros, etc.

O maior número de simulações, portanto, ocorre na área de processos, utilidades, manutenção, craqueamento catalítico, destilação e hidratação, transferência e estocagem, com 40 simulados por ano e 8 por turno.

Sveiby (1998, p. 106) confirma que a melhor forma de transferência do conhecimento tácito é aquela que permite ser interiorizada; é por isso que os jogos, as simulações e a representação e papéis são eficazes para transferir conhecimento. Perguntado sobre a contribuição dessas simulações para o aprendizado das equipes, os entrevistados responderam à questão com alternativas de respostas fechadas e de simples escolha. Os dados destacam que a prática da simulação preventiva contribui muito para a aprendizagem organizacional, num índice de $71,79 \%$.

Considerando que a aprendizagem ocorre com o exercício da prática, os simulados trazem características que facilitam a aquisição do conhecimento, seguindo uma ordenação, tendo como parâmetro um plano de emergência já elaborado, interpretado por Valle (2003, p. 182) como "a jogada ensaiada que o técnico apresenta e discute com o time antes do jogo, mostrando as jogadas".

Assim, no momento em que a pesquisa confirma que a realização de simulações preventivas contribui muito para o aprendizado, reporta-se aos pressupostos de Garvin (2002, p. 132) ao proferir que os problemas simulados oferecem solução, são projetados com habilidades específicas em mente e se 
apresentam de muitas formas, desde os mais simples ao mais complexos e desafiadores em que a aprendizagem associada se apresenta de forma física, social ou cognitiva.

Confirma Garvin (2002) que as melhores simulações combinam realismo, variedade e baixo risco, estando presentes o conflito e as dificuldades, sem esquecer de um elemento surpresa como essencial, assegurando que os que aprendem sejam atraídos e ajam com seriedade. A constatação do estudo acerca das afirmações encontradas é a de que esta prática de aprendizagem contribui muito, assegura que a organização de estudo se caracteriza como sendo uma organização de aprendizagem pelo processo da prática de simulações preventivas.

No intuito de saber se a Petrobras segue as normas certificadoras da ISO 14000 na prevenção a acidentes, foi perguntado: como as equipes estão lidando com as não-conformidades desta norma? As respostas foram fornecidas pelos entrevistados de forma espontânea, categorizadas as mais significativas como sendo o relato e discussão das não-conformidades, com 32 respostas, Implantação de ações corretivas, com 13 respostas, levantamento das causas básicas, com 11 respostas, a prevenção e as ações de melhorias com 6 respostas cada. Das respostas apreendidas cumpre ressaltar que a Repar já utiliza as RNC20, comprovado na pesquisa como uma das ações das equipes, por meio, especialmente, de relato e discussão das não-conformidades. A compreensão destas ações requer o conhecimento do que seja a não-conformidade e o estabelecimento da ISO 14000. A primeira, segundo a Fundação de Desenvolvimento Gerencial (2003, p.1) é o "Descumprimento de requisitos especificados". Exige, para sua existência, de estipulação de normas, essas, definidas pelo mesmo autor, como um "Documento que formaliza certo nível de consenso a respeito do que foi discutido. Aquilo que é estabelecido como base para a realização ou avaliação de alguma coisa. Princípio, regra, lei. Pode-se afirmar que norma é um "padrão obrigatório".

Neste caso, as conformidades são regidas pela NBR ISO 14000, uma série de Normas da International Organization for Standardization, dirigidas para a gestão ambiental, cujo objetivo é prover às organizações os elementos de um sistema de gestão ambiental que busca equilibrar a proteção ambiental e a prevenção de poluição com as necessidades socioeconômicas. Carvalho \& Romero (2003) apresentam a estruturação Básica da Série de Normas NBR ISO 14000, que estabelece um padrão de Sistema de Gestão Ambiental por meio de ferramentas apropriadas e economicamente viáveis para o negócio.

No Brasil, segundo Valle (2003), a Lei Federal n ${ }^{\circ}$ 9.966, de 28 de abril de 2000, dispõe sobre a prevenção, o controle e a físcalização da poluição causada por lançamento de óleo e outras substâncias nocivas ou perigosas em águas sob jurisdição nacional. Salienta algumas soluções que objetivam a prevenção dos acidentes, tas como barreiras de contenção, fixas ou móveis, uso de dispersantes químicos e uso de absorventes, materiais capazes de reter grandes volumes de líquidos em sua estrutura. Entretanto, ressalta Valle (2003), essas soluções devem estar conjugadas com dois fatores imprescindíveis: $i$ ) disponibilização dos materiais e equipamentos em pontos estratégicos para serem deslocados no curto prazo para o local de ocorrência do acidente e ii) participação de equipes treinadas para atuar em situações de emergência com amplo conhecimento sobre o uso desses materiais e equipamentos.

Ciente das disposições que a Lei determina, o que se encontrou na pesquisa sobre as nãoconformidades da norma ISO 14000 na REPAR, está de acordo com o desejado pela organização, assim explicitado: a organização do estudo possui os recursos e os equipamentos sugeridos como solução para casos de acidentes ambientais, como derrame de óleo; porém, ainda que se reconheça a Petrobras como organização de aprendizagem, reportando-se ao tempo do derrame de óleo ocorrido em 2000, não se configurava, à época, o domínio técnico das práticas de aprendizagem. Neste contexto, destacam-se as práticas adotadas a partir do evento, como a prática da simulação preventiva, entre outras, que capacita o empregado tanto ao conhecimento quanto à ação com as medidas corretivas.

\footnotetext{
${ }^{20} \mathrm{RNC}$ - Relatórios de não conformidades
} 
Confirmando as formas com que as equipes estão lidando com as não-conformidades da norma ISO 14000, a categoria principal desta discussão de resultados enuncia como medida corretiva e, possivelmente, preventiva, o relato e a discussão das não-conformidades, seguida da implantação de ações corretivas, do levantamento das causas básicas de prevenção, ações reativas, como o tratamento para não reincidência, baseando-se em ações de melhoria que encontram eco no depoimento sobre o atendimento à norma referida: "A norma estabelece parâmetros, é muito complicado explicar às pessoas que é coerente. Normalmente, as normas de qualidade são percebidas como entraves à criatividade. Dessa forma, dificilmente pode-se contar com a norma para ensinar questões ambientais. A lei diz qual a punição para quem não a pratica, mas não como deve ser a prática" (Entr. 28).

Esta interpretação compreende também os desígnios legais que estipulam projetar organizações expostas a riscos, em learning organization, uma vez que a conscientização dos fatos e das conseqüências do derrame de óleo atinge seus responsáveis, registrado na seguinte descrição: "Este é um investimento de longo prazo. Quanto mais internalizados estivermos das boas práticas, mais rápida, correta e segura é a atuação em momentos de não-conformidades. Aprender só com as próprias experiências não é um modelo ideal. É necessário investir no conhecimento, no treinamento na mudança de atitude" (Entr. 13).

Ao identificar práticas de aprendizagem organizacional relacionadas ao processo de prevenção de acidentes ambientais presentes no período de estudo na REPAR, interpreta-se a questão do roteiro apresentada com alternativas fechadas e de múltipla escolha, a partir da Tabela 1.

A análise da presença das diversas práticas de aprendizagem na REPAR no período de 2000 a 2002 atém-se a examinar as que estavam presentes em 2000 e as que se mantêm até 2002, além de estudar as respectivas evoluções em práticas específicas, e quais práticas defendidas pelos autores que fundamentam este estudo estão presentes na organização.

Observa-se que a prática da universidade corporativa, presente desde 2000, teve uma evolução considerável no período analisado, passando de $41,03 \%$ para $84,62 \%$ de presença na organização. Sobre esta prática, Meister (1999, p. 23) comenta que o resultado desejado com este tipo de aprendizagem é o de aprender fazendo, desenvolver a capacidade de aprender e dar continuidade a esse processo no trabalho executado. A emergência das universidades corporativas incita as organizações a reestruturarem seus ambientes de aprendizagem, para que sejam proativos, centralizados, determinados e realmente estratégicos por natureza.

Uma outra performance positiva presente na REPAR, no período analisado, envolve a prática de aprender ao treinar, saltando de $64,10 \%$ para $82,05 \%$, que evidencia a experimentação e a aquisição de uma reflexão mais detalhada, considerando-se as formas não convencionais de treinamento formal. Fleury e Fleury (1995, p. 66) lembram que, ao ser comprado um equipamento complexo, a empresa vendedora fornece treinamento aos futuros vendedores, uma forma de aprendizagem a ser considerada.

Tabela 1 - Práticas de aprendizagem presentes na REPAR de 2000 a 2002

\begin{tabular}{|c|c|c|c|c|c|c|}
\hline Alternativa & $\begin{array}{c}\text { Contagem } \\
2000 \\
\end{array}$ & $(\%)$ & $\begin{array}{c}\text { Contagem } \\
2001 \\
\end{array}$ & $(\%)$ & $\begin{array}{c}\text { Contagem } \\
2002 \\
\end{array}$ & $(\%)$ \\
\hline E-learning & 8 & 20,51 & 13 & 33,33 & 15 & 38,46 \\
\hline Benchmarking & 22 & 56,41 & 25 & 64,10 & 27 & 69,23 \\
\hline Universidades Corporativas & 16 & 41,03 & 24 & 61,54 & 33 & 84,62 \\
\hline Comunidades de Estudo & 9 & 23,08 & 17 & 43,59 & 21 & 53,85 \\
\hline Tecnologia da Informação & 19 & 48,72 & 23 & 58,97 & 25 & 64,10 \\
\hline Visitas Técnicas & 20 & 51,28 & 23 & 58,97 & 31 & 79,49 \\
\hline Utilização de Arquétipos de Sistema & 9 & 23,08 & 15 & 38,46 & 14 & 35,90 \\
\hline Mapeamento dos Dilemas Estratégicos & 7 & 17,95 & 10 & 25,64 & 11 & 28,21 \\
\hline Exercício da Coluna da Esquerda & 4 & 10,26 & 5 & 12,82 & 5 & 12,82 \\
\hline Solução de Problemas de Maneira Sistemática & 19 & 48,72 & 21 & 53,85 & 23 & 58,97 \\
\hline Experimentação & 14 & 35,90 & 20 & 51,28 & 21 & 53,85 \\
\hline Aprendizado com as Próprias Experiências & 26 & 66,67 & 30 & 76,92 & 31 & 79,49 \\
\hline Aprendizado com Outros & 21 & 53,85 & 26 & 66,67 & 26 & 66,67 \\
\hline
\end{tabular}




\begin{tabular}{|c|c|c|c|c|c|c|}
\hline Transferência de Conhecimento & 20 & 51,28 & 22 & 56,41 & 25 & 64,10 \\
\hline Aprender pela Análise do Desempenho & 15 & 38,46 & 16 & 41,03 & 20 & 51,28 \\
\hline Aprender ao Treinar & 25 & 64,10 & 29 & 74,36 & 32 & 82,05 \\
\hline Aprender por Contratação & 15 & 38,46 & 24 & 61,54 & 26 & 66,67 \\
\hline Aprender por Busca & 16 & 41,03 & 18 & 46,15 & 21 & 53,85 \\
\hline Outras & 3 & 7,69 & 2 & 5,13 & 4 & 10,26 \\
\hline Não responderam & 6 & 15,38 & 6 & 15,38 & 3 & 7,69 \\
\hline Total de entrevistados & 39 & 100,0 & 39 & 100,0 & 39 & 100,0 \\
\hline
\end{tabular}

Fonte: Levantamento de campo, 2003.

Refletindo o aprendizado com as próprias experiências não tem apresentado evolução no período analisado pela pesquisa, com apenas $12,82 \%$ de presença em 2002 a mais do que no ano do derrame de óleo. $\mathrm{O}$ aprendizado com as próprias experiências é assim interpretado pelos entrevistados: "Tem seu lado positivo, mas não é completo. Aliado às próprias experiências, temos necessidade de captar boas práticas e aprender a prevenir ou evitar experiências negativas de outros e exercitar ou adequar as suas experiências positivas" (Entr. 17).

Por sua vez, a prudência é assim desenhada: "Em determinadas áreas do conhecimento é um processo bastante adequado, mas, em operação de processos petroquímicos essa prática é bastante perigosa. A Experiência muitas vezes se repete pelo erro (posso estar há 10 anos fazendo a mesma coisa ... de forma errada) (Entr. 28).

A constatação a que se chega sobre a presença das práticas é de que as mesmas já existiam à época do derrame de óleo. Contudo, a sua freqüência não se faz relevante em nenhum momento, se não for acompanhada da respectiva aprendizagem organizacional a respeito da importância que cada uma dessas práticas representa na prevenção a acidentes ambientais.

Lembra Davenport (1998, p. 107) que o conhecimento é transferido nas organizações, quer seja gerenciado ou não esse processo e exemplifica com uma visita técnica: quando um funcionário pergunta a um colega da sala ao lado como ele poderia elaborar um orçamento que lhe foi pedido, está solicitando uma transferência do conhecimento. Numa outra situação, quando um representante de vendas que é novo numa dada região pergunta ao colega prestes a se aposentar quais as necessidades de determinado cliente, eles também estão trocando conhecimento.

No sentido de investigar o grau de comprometimento, a pesquisa perguntou: "Você se sente envolvido e comprometido com a disseminação de práticas de prevenção a acidentes após a sua capacitação formal?". As respostas, recebidas de forma objetiva, confirmam o comprometimento com $92,31 \%$ de respostas "Sim" e 2,56\% de respostas "Não".

Por certo, o comprometimento é parte implícita no contrato e na conscientização do empregado da REPAR quanto à disseminação do conhecimento na prática de prevenção a acidentes.

Mayo (2003, p. 122), valendo-se dessa fórmula, entende que se trata de uma combinação que conduz ao desempenho e ao esforço máximo por meio do comprometimento. Nesta descrição, o esforço é entendido como a aplicação consciente de recursos físicos e mentais na direção de um determinado fim, pela aplicação ou retenção do esforço, nós controlamos quando, onde e como da contribuição do capital humano.

Deste modo, quando os entrevistados da REPAR confirmam o seu envolvimento e comprometimento com a disseminação da prática de prevenção a acidentes, tais atos estendem-se além da conscientização sobre a segurança na Unidade, mas expressam a percepção do indivíduo com relação ao seu papel de aprendiz e de transmissor de conhecimento na organização. A freqüência com que ocorre o comprometimento na REPAR, segundo os dados fornecidos pelos funcionários, permite a intervenção de Mayo (2003) sobre os efeitos visíveis decorrentes do alto comprometimento e da motivação, quando as pessoas trabalham com empenho, preparadas para assumirem tarefas extras e disponíveis a se envolverem em vários aspectos da organização. 
Skinner (1997) argumenta que conquistar a lealdade de centenas ou milhares de indivíduos em uma empresa na intenção de que direcionem suas energias em prol das metas da empresa é tarefa difícil. É o caso em que os relacionamentos eficazes entre indivíduos e empresas baseiam-se na confiança dos funcionários de que existe uma ligação entre essas metas, exigindo superação de más experiências.

Sobre mudanças no processo de prevenção a acidentes depois do evento ocorrido em 2000, com respostas de simples escolha, $89,75 \%$ dos funcionários admitiram a sua existência, enquanto $2,56 \%$, responderam não e, sobre quais as mudanças ocorridas, os respondentes indicam que Programa para estabelecer cultura em segurança como o STOP, DDS, ISO, PSP; investimento em treinamento; revisão e mudanças nos procedimentos; mudança de cultura e de visão, dentre outros.

O reconhecimento de que os programas implementados pela Petrobras no estabelecimento de cultura de segurança, aliado a investimentos em treinamentos, mais destacados nas entrevistas, e todas as demais práticas relacionadas permitem deduzir que a organização adota as práticas de aprendizagem organizacional com o intuito de promover mudanças na cultura e na conscientização de todos os envolvidos na empresa de estudo.

Com a chamada de que: "Mudança de visão (muito em custo). Hoje o foco é a segurança no processo, com o foco custo em segundo plano" (Entr. 27), é possível interpretar a referência entre as mudanças e suas contribuições: nem todas as respostas conduzem ao mesmo pensamento. Há casos, como o depoimento a seguir descrito, em que se destaca a crítica registrada acerca desta contribuição: "Diminuiu o percentual de arrogância" (Entr, 28), que destoam das afirmações: "Maneira de enxergar as coisas e suas conseqüências. Mudam os conceitos, certas coisas que pareciam não ter importância passaram a ser tratadas com impacto" (Entr. 14).

Dados como aumento da segurança e um novo padrão na eficiência e eficácia no SMS fazem jus a uma nova visão que a organização do estudo busca implantar em acordo com os programas de segurança, prevenção a acidentes ambientais e aprendizado. Para finalizar, o depoimento confirma: "Total eliminação de horas de afastamento da força de trabalho (pessoal próprio + contratado)" (Entr. 16).

Considerando se a capacitação contribuiu com as mudanças ocorridas no processo de prevenção a acidentes, em questão de simples escolha, $94,87 \%$ das respostas confirmaram que sim, e 5,13\% que não contribuiu. As contribuições das capacitações ocorridas, na visão dos entrevistados foram: conscientizou sobre as responsabilidades individuais na execução das tarefas, com $84,62 \%$; conscientizou da responsabilidade social da organização, $74,36 \%$; tornou as ações operacionais/gerenciais mais seguras, 66,67\%; permitiu a troca de experiências, $61,54 \%$; aprendizagem sistemática operações exigidas pela ISO 14000, 56,41\%; possibilitou dirimir dúvidas, $46,15 \%$, entre outras.

A percepção dos entrevistados sobre a contribuição da capacitação na prevenção de acidentes é explanada nos índices apresentados na tabela acima. Percebe-se a ocorrência de mudanças de conscientização, em maior destaque, ocasionando, por sua vez, reações ativas nos setores gerenciais e operacionais. A prática da troca de experiência permitiu a aprendizagem na organização conforme dados registrados sobre a aprendizagem sistemática das operações preconizadas pelo ISO 14000, dados esses, que vêm ao encontro das indagações propostas no estudo.

Foi questionado ao entrevistado o que representa para ele aprender com as próprias experiências. As respostas espontâneas foram categorizadas a partir dos objetivos deste estudo, obtendo destaque: i) reconhecimento do erro; ii) a aprendizagem com as próprias experiências; iii) aquisição de conhecimentos; iv) a oportunidade de melhoria contínua; v) reconhecer os erros e não repeti-los; vi) a reflexão sobre os fatos e vii) a revisão de conceitos, postura profissional e de procedimentos.

Observando-se as categorizações selecionadas, ditadas pelos entrevistados como palavras-chave para definir a aprendizagem pelas próprias experiências, cabe o conceito de Kaplan (1964, p. 144-7, apud 
Garvin, 2002, p. 185) sobre a experimentação como um processo de aprendizagem a ser realizado em uma situação característica, pois "o que as experiências podem fazer é minimizar os erros de observação que são inseparáveis de encontros causais ou, pelo menos, de encontros não planejados".

Lembra Garvin (2002) ainda que a minimização dos erros requer que a experiência atenda a duas condições: devem demonstrar, com alto grau de confiança, que uma mudança em uma variável efetivamente causa uma mudança em outra e os resultados devem generalizar além do cenário experimental.

As razões descritas pelos entrevistados para as próprias experiências possuem diferentes conotações individuais, das quais se destacam: "Quando analiso o que fiz e consigo ver no que errei e no que acertei, ou mesmo quando vejo a experiência dos outros, como fizeram e no que erraram, estas experiências servem de aprendizado. Só se aprende se tem a disposição de refletir sobre os fatos"(Entr. 14).

Noutra fala: “A melhoria continua dos processos que já é uma filosofia praticada internamente. Existem grupos de melhoria continua que passaram a fazer parte do PSP que discute as experiencias a partir das causas básicas e ações que devem ser tomadas para que os erros não se repitam"; "Representa a fixação de conhecimentos. Através da experiência eu consigo identificar o que realmente é importante para desempenhar a minha função" (Entr. 38 e 15, respectivamente).

Na afirmação de que errar é também uma forma de aprender, foi solicitado ao entrevistado que explicasse por quê. As respostas foram concedidas de forma espontânea e categorizadas, apresentadas a seguir: Aprender com os próprios erros; O erro permite revisão de conceitos e formas de atuação; Os erros desencadeiam o aprimoramento do indivíduo; A punição pelo erro não leva ao aprendizado e O erro ocorre por desconhecimento e prática.

A detecção e o reconhecimento do erro fica latente nas respostas espontâneas fornecidas na pesquisa, apresentadas na íntegra, quee permitem categorizar os principais reflexos dos sentimentos e percepções dos entrevistados, pela abertura que lhes foi concedida pela entrevista e expressada numa fala que assume uma situação pregressa e condiciona ações futuras, como pode ser observado a seguir: "Porque através dos erros podemos buscar e reformular novas formas de desempenhar a mesma tarefa. Neste processo, a busca pelo acerto muitas vezes supera a primeira execução correta da atividade, portanto, os erros nestas circunstâncias desencadeiam o aprimoramento do indivíduo" (Entr. 8).

$\mathrm{Na}$ frase descrita, a percepção da pesquisadora interpreta que, além do reconhecimento do erro, ao exercer a prática da aprendizagem a partir das próprias experiências, o entrevistado executa a aprendizagem organizacional em seu aprimoramento individual. Trata-se de um mérito das mudanças ocorridas na REPAR, ou seja, são o resultado da adoção das práticas de aprendizagem preconizadas por Garvin (1993).

Outra transcrição que impactou nos resultados da pesquisa e que confirma a evolução do aprendizado organizacional é a seguinte: “... O nosso maior exemplo foi no vazamento para o Rio Barigui. Todos se uniram. Foram estudadas medidas preventivas e preditivas. A punição não contribui. É melhor investir (gastar dinheiro) em conscientização, treinamento, mudança de cultura" (Entr. 13); e, "Na gerência pelo medo do erro não leva a nenhum aprendizado. Se a organização ou a pessoa erra, existem causas e conseqüencias para fazer melhor e entender por que não deu certo. Dessa forma, o erro pode ser fonte de aprendizado" (Entr. 14), corroborando o comentário de que a REPAR, ainda com ressalvas, é uma organização da aprendizagem.

As ações preventivas, intrinsecamente ligadas ao problema de pesquisa da proposta de estudo, sobre a contribuição da melhoria das práticas de aprendizagem na prevenção a acidentes, são confirmadas na citação: "Porque o erro chama atenção de forma mais intensa do que o acerto e assim as informações são fixadas mais significativamente. Também por que em cima do erro são abertos canais de 
discussão. Operacionalmente falando sobre controle de processos (SDCD) muitas ocorrências não se repetem com a freqüência adequada para um aprendizado com retenção de informação, assim quando erros acontecem ocorre uma retenção mais significativa. Hoje estamos começando a resolver este problema com a aplicação de simuladores de processo" (Entr.21).

Posto este registro, encontra-se nos dados da pesquisa a importância de aprender, pois "Com o erro também, pode-se deflagar o processo de aprendizado, pela reflexão e análise crítica das ocorrências inadequadas, possibilitando experiência. Há uma frase que resume esta questão atitudes adequadas vem da experiência e a experiência vem das atitudes inadequadas" (Entr. 32).

Mais uma resposta sobre a aprendizagem com os erros é dada nesta entrevista: "Quando o erro é visto como instrumento de punição ele não leva ao aprendizado. Será uma forma de aprender desde que haja diretrizes que tratem o erro como um instrumento de aprendizado e não como sistema de conseqüências, ex. demissões. A filosofia da empresa é voltada para o aprendizado afim de que se possa dar saltos qualitativos, portanto se o erro for usado desta forma sim, ele é uma forma de aprender" (Entr. 38).

Por fim, para reconhecer o tratamento sobre as não conformidades com as normas da ISO 14000, se elas são discutidas e estudadas suas causas, e seu resultando considerado como uma fonte de aprendizado, solicitou-se ao entrevistado apor a sua opinião. Categorizados os resultados, temos: $i$ ) o problema seria corrigido, mas não deveria ocorrer a não-conformidade; ii) quando do tratamento da não conformidade, a análise das causas levam a ações que permitam retomar o padrão; iii) todas as não-conformidades, após analisadas nos dão aprendizado; iv) ocasionando um melhor entendimento das metas da iso $14000 ; v$ ) deixarmos de cometer os mesmos erros; porque são fatos e dados concretos, com conseqüências reais.

Considerando que a interpretação das categorias apresentadas no quadro acima compreende a ligação direta com a ISO 14000, a utilização das RNC nas organizações, deste modo, pode ser entendida não como a revelia às normas da ISO 14000, mas um longo reajuste dos erros cometidos, conforme se comprova no depoimento obtido na pesquisa: "Sim, porque quando do tratamento da não conformidade, a análise das causas levam à ações que permitam retomar o padrão, ou ainda, levam a inovações que adotadas resultam em saltos de qualidade melhorando o padrão anterior, proporcionando uma fonte de aprendizado e de melhoria de conhecimento e prática" (Entr. 32). Mais ainda, quando o entrevistado manifesta a sua percepção e conscientização de que: “... A princípio todas as RNCs devem ser discutidas e estudadas. Isso somente bastaria para tornar-se um aprendizado. Mas, a partir dela, pode-se transformar-se em mais ações preventivas do que aquelas objetos das RNCs" (Entr. 39).

Sobre o aprendizado originado pelo estudo e análise das RNC, o que os entrevistado têm a dizer reflete-se aqui: "Se discutidas, estudadas e colocadas em prática, levaria a uma diminuição nas lacunas da empresa e o aprendizado seria também empírico" (Entr. 9). O aprendizado é sempre a inserção de dados novos, informações compartilhadas e conhecimento adquirido; seguindo-se o que indica a entrevista: "Sim, porque com as não-conformidades existe a possibilidade de avaliar a causa básica e as propostas de melhorias. Os procedimentos analisados permitem as melhorias implementadas" (Entr. 7), devem ser aproveitados os conselhos inseridos nesta recomendação: "Com certeza todas as não-conformidades devem ser eliminadas para não serem repetidas e isso é uma fonte riquíssima de aprendizado" (Entr. 23).

No tocante a ISO 14000, ela foi proposta como um conjunto de normas que visam manter a integridade do meio ambiente. A lembrança de que a natureza é um condomínio social e de que as chagas abertas podem ser sentidas por todos os ocupantes é reforçada pela designação: "a natureza sobre a que voltamos nossos novos olhos neste final do século XX já não é idílica senão que está enferma: de ser ameaçante passou a ser ameaçada. Esse é o novo e o diferente. E se dá a circunstância de que somos nós, a espécie da hybris, o desdobramento da consciência da Natureza mesma, os causantes da enfermidade e da ameaça" (FREITAS, 2003, p. 54). 
Na ponta deste fio condutor, é o capital humano que conduz às práticas de aprendizagem organizacional, e que fará a diferença na manutenção do desenvolvimento sustentável e na prevenção a acidentes ambientais através da análise das próprias experiências. No tocante às mudanças, a intenção foi conhecer de que forma as pessoas da equipe reagem diante da necessidade de mudanças no processo que executam há muito tempo, responderam: sentem dificuldades, mas acabam aceitando as mudanças com 71,79\%; reagem positivamente a mudanças, $23,08 \%$; resistem às mudanças, $20,51 \%$; compreendem, mas continuam executando suas ações como sempre fizerem, 12,82\%.

Os dados acima, ainda que destaquem a aceitação dos entrevistados às mudanças, contêm a ressalva de que eles sentem dificuldades em tal atitude, enquanto que grande parte deles resiste ou simplesmente, não mudam.

A utilização desta fundamentação na pesquisa bibliográfica é justificada em virtude de ter-se o cuidado em inferir na liberdade que o indivíduo possui, enquanto cidadão, de conservar suas crenças e valores. Infelizmente, com as respostas obtidas, entende-se que a conscientização dos entrevistados não alcançou o patamar da excelência de que a REPAR necessita quando se trata de um tema tão importante quanto urgente: mudar para aprender e prevenir para minimizar riscos.

\section{Conclusão}

Este estudo teve como tema central as práticas de aprendizagem organizacional, as quais foram fundamentadas no constructo teórico e que, para esta análise, considerou as práticas de aprendizagem organizacional implantadas nos processos de prevenção a acidentes ambientais da REPAR no período compreendido entre 2000 a 2002.

A empresa estudada pertence ao setor de refino de petróleo, possui um processo produtivo considerado de alto risco, por envolver fatores agressores ao meio ambiente e que sofreu a experiência de um derrame de óleo em torno de sua refinaria em 2000, cujo impacto ambiental afetou a organização como um todo.

Mudanças estratégicas, legais e operacionais foram implantadas para vencer os desafios impostos por legislação e pela sociedade para o controle eficaz na prevenção a acidentes industriais. Implantar estas novas ações exigiu da empresa novos aprendizados.

As ações do processo de prevenção a acidentes ambientais presentes na REPAR, no período de 2000 a 2002, foram os simulados de acidentes, uma das práticas de aprendizagem organizacional que possibilita a diminuição de acidentes e aumenta a conscientização dos envolvidos no processo de produção da empresa.

A partir de 2001, foram levantadas ações como auditorias comportamentais, projetos, investimentos em equipamentos, planos de contingência, ênfase em eficácia na manutenção, revisão de procedimentos mudança de tubulação, investimentos operacionais e em segurança. Ao mesmo tempo, houve, em 2001, ações de planejamento de sistemas para atendimento a acidentes envolvendo níveis técnico, gerencial e operacional, das quais os resultados são registrados como um reforço à cultura organizacional voltada a visão preservacionista.

Após o derrame de óleo de 2000, a REPAR, passou a cumprir com mais rigor a Resolução Conama $\mathrm{N}^{\circ}$ 001, realizando a conservação do meio ambiente e a prevenção a acidentes ambientais, gerenciando seu processo produtivo de modo a atender a essas determinações legais, bem como a adequar suas ações nos moldes da ISO 14001, da ISO 9002 Qualidade, de modo a assegurar a qualidade dos derivados produzidos na REPAR, cuidar do meio ambiente, controlar o impacto de suas atividades e, também da OHSAS 18001 Segurança e Saúde, como empresa certificada e adequada aos requisitos que permitem um maior controle dos riscos de acidentes e doenças ocupacionais. 
Apesar de novas ações terem sido implementadas no processo de prevenção a acidentes ambientais, ao longo do período deste estudo, a pesquisa mostra que a REPAR ainda não consolidou seu processo de mudança em relação à prevenção. $\mathrm{O}$ foco em alta produtividade, com menor custo, sofre intenções de mudanças no período estudado, buscando produtividade segura.

Constatou-se também uma lacuna existente entre o discurso e a prática, evidenciada no hiato existente, a partir dos relatos verbais acerca de segurança, prevenção a acidentes e, em paralelo, a cobrança pelo aumento da produtividade imediata. Apesar das ações implementadas, das práticas cujos resultados apontam para uma melhoria significativa, a lacuna existe é desafiadora, o que também estimula a empresa a dar continuidade nas práticas adotadas em busca de produção segura para a empresa como um todo e para o meio ambiente em que está inserida.

Atendendo ao segundo objetivo proposto, a pesquisa identificou as práticas de aprendizagem organizacional, tanto no nível gerencial como operacional, relacionadas com o processo de prevenção de acidentes ambientais na REPAR, no presente ano de 2000 e reforçadas a partir da implementação da Agenda de Mudanças. Algumas das práticas de aprendizagem organizacional apresentaram uma evolução significativa, como o aprendizado com as próprias experiências, o qual mostrou um impacto de $12,82 \%$. Este mesmo índice também se repetiu na prática de transferência de conhecimento e na prática de aprendizado com outros. Na prática da experimentação, o impacto foi de 17,95\% no mesmo período, mesmo índice que evoluiu na prática de aprender ao treinar, no período em estudo.

Estas práticas, adotadas pela REPAR em meados de 2000, sofreram intensificação das existentes e implantação de novas a partir da Agenda de Mudanças, em 2001. Constatou-se que a medida em que ocorreu a evolução na adoção dessas práticas, a empresa passou a registrar redução de acidentes ambientais. As ações de simulações preventivas, tais como DDS, STOP, auditorias comportamentais e certificações também permitiram mudança cultural nos processos operacionais e gerenciais da REPAR.

Reforçam esta conclusão os dados da pesquisa documental registrados na Agenda de Mudanças, voltados à Gestão do Conhecimento, que englobam as práticas de aprendizagem utilizadas para disseminar o conhecimento na organização.

Constatou-se ainda que o objetivo de analisar a relação existente entre as práticas de aprendizagem organizacional, apontadas na literatura, e as implementadas no processo de prevenção de acidentes ambientais na REPAR, no período de estudo, confirmam as práticas constantes no constructo teórico, como as mesmas implementadas no processo de prevenção a acidentes ambientais na REPAR, no período de 2000 a 2002. Além disso, práticas de aprendizagem organizacional como o benchmarking, por exemplo, foram constatadas na pesquisa documental como adotada pela REPAR antes de $2000 \mathrm{e}$ obteve um impacto relevante no período analisado.

Os resultados obtidos atenderam ao objetivo principal do estudo,ou seja, proporcionaram a análise das práticas de aprendizagem organizacional e do impacto propiciado pelas mesmas no processo de prevenção de acidentes ambientais na REPAR. Isso se confirma pelos dados obtidos na pesquisa de campo, o que fornecem suporte ao estudo e comprova a evolução gradativa das práticas de aprendizagem organizacional, bem como a redução nos índices de acidentes e afastamentos ao longo do período analisado.

\section{Referências}

ARGYRIS, C. Ensinando pessoas inteligentes a aprender. In: HOWARD, Robert. Aprendizado organizacional: gestão de pessoas para a inovação contínua. Rio de Janeiro: Campus, 2000.

ARGYRIS, C et al. Aprender a aprender. HSM Management, n. 8, ano 2, p.58-64, Jul. 1998.

BOWDITCH, J. L. Elementos de comportamento organizacional. São Paulo: Pioneira, 1992. 
BONTEMPO, M. A sociedade planetária. São Paulo: Best Seller - 2. ed. 1999.

BOSCO, F. Rumo à auto-suficiência. Petro \& Química. Edição 252, Matéria de capa, Set. 2003.

CALMON, K. A avaliação de programas como instrumento de aprendizagem organizacional: o caso do PROSEGE. Brasília: Universidade de Brasília, 1997. 192p.

CONAMA - Conselho Nacional do Meio Ambiente - Resolução No 001, de 23 de janeiro de 1986.

DAVENPORT, T. H. Conhecimento empresarial: como as organizações gerenciam o seu capital intelectual. 6. ed. Rio de Janeiro: Campus, 1998.

DEMAJOROVIC, J. Da política tradicional de tratamento do lixo à política de gestão de resíduos sólidos. Revista de Administração de Empresas. São Paulo, v. 35, n. 3, p. 88-93 mai/jun 1995.

DODGSON, M. Organizational learning: a review of some literatures. Organizational Studies.V.14 n3,p.375-394. 1993

Dicionário Mirador Internacional Enciclopédia Britânica do Brasil. Publicações Ltda. S. Paulo,1975. p.169 vol. 1

Dicionário Enciclopédia Século XX. Rio de Janeiro: Olympio Expressão e Cultura, 1972. vol 1. p. $133-4$.

FLEURY, A.; F. M. T. L. Aprendizagem e inovação organizacional: as experiências de Japão, Coréia e Brasil, São Paulo: Atlas, 1995.

FREITAS, M. Acidentes industriais ampliados: desafios e perspectivas para o controle e a prevenção. Rio de Janeiro: FIOCRUZ, 2000.

FREITAS, P. Direito ambiental em educação 3. Curitiba: Juruá, 2003.

GARVIN, D. Building a Learning Organization. Harvard Business Review, July-August, 1993. . Aprendizagem em ação: um guia para transformar sua empresa em uma learning organization. Rio de Janeiro: Qualitymark, 2002.

HAWKEN, P; LOVINS, A; LOVINS, L. H. Capitalismo Natural: criando a próxima revolução industrial. São Paulo: Cultrix - Amana-Key, 2000.

MAQUIAVEL, N. o PRINCIPA. 2 ED. Brasilia: EdUnB, 1992.

MACHADO, H; PORTO, S.; FREITAS, M. Perspectivas para uma análise interdisciplinar e participativa de acidentes (AIPA) no contexto da indústria de processo. In: FREITAS, Carlos Machado (Org.) Acidentes industriais ampliados: desafios e perspectivas para o controle e a prevenção. Rio de Janeiro: FIOCRUZ, 2000.

MAYO, A. O valor humano da empresa. Trad. Julia Maria Pereira Torres. São Paulo: Prentice Hall, 2003.

MERLEAU-PONTY, M. Fenomenologia da percepção. 2. ed. São Paulo: Martins Fontes, 1999.

NONAKA. I.; TAKEUCHI, H. Criação do conhecimento na empresa: 11. ed. Trad. Ana Beatriz Rodrigues, Priscilla Celeste. Rio de Janeiro: Campus, 1997. 
PETERS, T. Não é Hora de Moderação. Da Era da Estabilidade à Era da Incerteza.

$<$ www.uol.com.br/canalexecutivo/artigos.htm $>$

PEDRINI, G. (Org.) Educação ambiental: reflexões e práticas contemporâneas. Petrópolis: Vozes, 1997. p.15-21

PETROBRAS. Agenda de Mudanças - Projeto 7. 21 de Julho de 2001.

PETROBRAS. SMS na Petrobras. A Petrobras está comprometida em alcançar padrões

internacionais de segurança, meio ambiente e saúde, 2003.

REPAR. Com a população. Ano IV, B.31, ago. 2003.

. Para tem novos contextos. Ano IV. N. 34, nov. 2003.

. REPAR sedia reunião do CD/Sul. Ano IV, $\mathrm{n}^{\circ}$ 34. Nov. 2003. s.p.

. Novos operadores visitam a REPAR. Ano IV, $\mathrm{n}^{\circ}$ 34. Nov. 2003. s.p.

Revista Petrobras. Sem aviso. Ano 9. N. 87, jan.2003. p. 26-7.

. O desafio de criar a capacidade de refino. Ano 9. N. 93, out. 2003. p. 14.

RODRIGUEZ, Gestão empresarial: organizações que aprendem. Rio de Janeiro: Qualitymark:

Petrobras, 2002

ROSENBERG, J. e-Learning. São Paulo: Makron Books, 2002.

ROSSIN, A. C. Prevenção a acidentes Ambientais. São Paulo: CETESB, 1986.

SANTAELLA, L. A percepção: uma teoria semiótica. 2. ed. São Paulo: Experimento, 1998.

SENGE,P. A quinta disciplina. Arte, teoria e prática da organização de aprendizagem. S.Paulo:Best Seller, 1990.

A dança das mudanças. Rio de Janeiro: Campus, 1999.

STATA, R. O novo trabalho do líder: construindo organizações que aprendem. In: STARKEY, Ken. Como as organizações aprendem: relatos do sucesso das grandes empresas. São Paulo: Futura, 1997. p. 376-396.

VALLE, E. Meio Ambiente: acidentes, lições, soluções. São Paulo: Editora Senac, 2003.

YIN, R. Estudo de caso: planejamento e métodos. 2. ed. Porto Alegre: Bookman, 2001. 